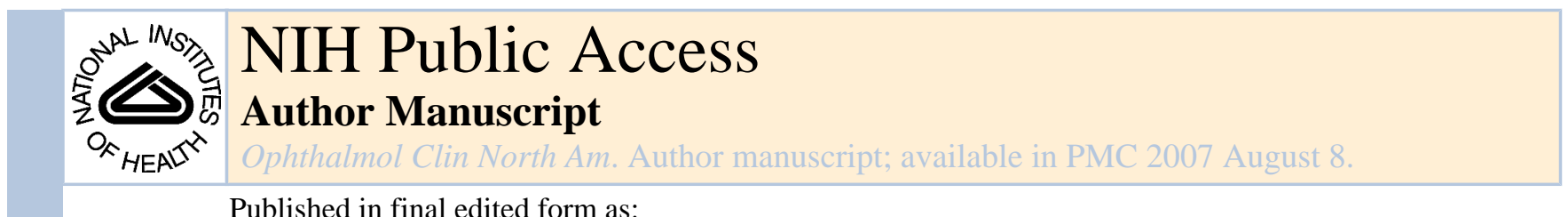

Published in final edited form as:

Ophthalmol Clin North Am. 2004 March ; 17(1): 33-52.

\title{
Imaging in glaucoma
}

Daniel M. Stein, BA, Gadi Wollstein, MD, and Joel S. Schuman, MD

UPMC Eye Center, Department of Ophthalmology, University of Pittsburgh School of Medicine, The Eye and Ear Institute, Suite 816, 203 Lothrop Street, Pittsburgh, PA 15213, USA

The detection and monitoring of glaucoma are multifactorial processes traditionally involving several diagnostic modalities, including intraocular pressure measurements, subjective evaluation of the optic nerve head $(\mathrm{ONH})$, and visual field testing. These traditional methods of assessing glaucoma have several key limitations that dictate the need for supplementary approaches. Intraocular pressure is the major identified risk factor for the development of glaucomatous damage, and lowering intraocular pressure serves to impede the progression of retinal degenerative change [1-3]. Nevertheless, the high interindividual variability and the diurnal variation in the intraocular pressure have limited the use of this parameter for the detection of the disease. Moreover, intraocular pressure values do not indicate whether damage has occurred, or to what extent. Visualization of the ONH in glaucoma by ophthalmoscopic examination or serial stereoscopic photographs is highly dependent on observer skills, inducing high interobserver and intraobserver variation that affects the utility of this diagnostic modality $[4,5]$. Visual field analysis through automated perimetry is a widely used technique that is arguably the gold standard to evaluate glaucomatous neuropathy and to monitor disease progression. Although it is sensitive and specific for detecting functional visual field loss, automated perimetry has several significant limitations [6-9]. The test requires the subjective input of the tested individual; therefore, it is prone to high short- and long-term fluctuation. This unavoidable source of error necessitates multiple retesting to improve the reliability of the technique, delaying the recognition of glaucomatous damage [10]. Furthermore, numerous studies have shown that glaucomatous field abnormalities may be preceded by structural changes of the ONH [11-13] and nerve fiber layer [14-17].

Because glaucomatous damage is largely irreversible, it is imperative to identify accurately eyes with early structural changes, because they are at risk for continued injury. It has been suggested that the earlier glaucoma is detected and treated, the greater the likelihood that medical or surgical intervention will delay or prevent the progression of glaucomatous neuropathy and subsequent functional impairment [18-20]. This assumption underscores the need for accurate and reproducible quantitative evaluation of the eye. Beyond early detection, quantitative imaging devices might be a more sensitive way to detect glaucomatous progression when compared with clinical qualitative assessments.

Work during the past two decades has resulted in the development and implementation of several imaging technologies designed to detect glaucomatous neuropathy at early stages of disease. This review outlines several of the most current imaging technologies, including confocal scanning laser ophthalmoscopy (CSLO), scanning laser polarimetry (SLP), optical coherence tomography (OCT), and the retinal thickness analyzer (RTA). The technologic underpinnings, sensitivity and specificity, and clinical studies of each method are discussed.

* Corresponding author. E-mail address: schumanjs@ upmc.edu (J.S. Schuman). 


\section{Confocal scanning laser ophthalmoscopy}

\section{Device fundamentals}

Confocal scanning laser ophthalmoscopy is a real-time imaging technique that is used to produce three-dimensional images of the $\mathrm{ONH}$. It is based on the principle of spot illumination and spot detection [22,23]. A spot of laser light is projected onto the tissue, and the reflected light is detected by a sensor. The system uses a pair of conjugated pinholes located in front of the light source and the light detector components. This pair ensures that only light reflected from a defined focal plane will reach the light detector. Light reflected from layers above or below the focal plane is not focused to the pinhole, leaving only a small fraction that can pass and be detected. Out-of-focus light is highly suppressed, and the suppression increases rapidly with increasing distance from the focal plane. The device moves the focal plane to acquire sequential images. Reconstructing the series of scans at the various focal planes creates a threedimensional topographic representation of the surface that is scanned.

The Heidelberg Retina Tomograph (HRT; Heidelberg Engineering, Heidelberg, Germany) is a CSLO device. The HRT uses a diode laser beam (wavelength, $670 \mathrm{~nm}$ ) and captures a series of 32 sequential two-dimensional scans in a total acquisition time of 1.6 seconds. The optical transverse resolution of the HRT is $10 \mathrm{~m}$ and the axial resolution $300 \mathrm{~m}$. The initial scans are focused anterior to the retina; the last scans are posterior to the bottom of the optic cup. The system allows three options for the field of view: $10 \times 10$ degrees, $15 \times 15$ degrees, or $20 \times 20$ degrees. For each focal plane, the HRT acquires $256 \times 256$ measuring points, recording a reflection intensity value at each of the particular $(\mathrm{x}, \mathrm{y})$ coordinates of the focal plane. The HRT registers and aligns the 32 consecutive scans to correct for eye movements that may occur during image acquisition. For each $(\mathrm{x}, \mathrm{y})$ point, the machine determines the surface location in the $\mathrm{z}$-axis derived from the center of gravity of the reflected light along the 32 scans. To calculate absolute z-axis measurements, a "zero-plane" is defined, which is determined by calculating the mean height of the peripapillary retinal surface as measured by a reference ring that is automatically defined at the periphery of the scan. The data from these measurements are color coded and presented as a topographic and reflective map (Figs. 1-3).

The operator is required to trace the $\mathrm{ONH}$ margin. Based on this contour line, the HRT operation software automatically defines the reference plane. This plane is located $50 \mathrm{~m}$ posterior to the mean surface height along a 6-degree arc at the inferotemporal region of the contour line. The reference plane is then used as a topographic cutoff. Structures below the plane are defined as optic cup and structures above the plane as neuroretinal rim.

Heidelberg Engineering has recently developed a second-generation HRT machine (HRT II). This device is essentially a small, lightweight, portable, and automated version of the original HRT. The transverse field of view is fixed to $15 \times 15$ degrees with a $384 \times 384$ measuring point grid in each of the scanned planes. The number of scanned planes ranges from 16 to 64 depending on the optic disk depth. This version uses an internal fixation target and automatically acquires three consecutive series of scans, shortening the duration of the image acquisition.

\section{Reproducibility}

Measurements with the HRT have been found to be highly reproducible in numerous studies [24-29]. Rohrschneider et al reported a standard deviation for each measuring point of $30 \pm 6$ $\mathrm{m}$ in glaucoma patients and $22 \pm 6 \mathrm{~m}$ in normal subjects [26]. The coefficient of variation $(\mathrm{COV})$ of the various HRT measurements in this study ranged from $2.9 \%$ to $5.2 \%$ in glaucomatous eyes to $3.3 \%$ to $4.6 \%$ in normal eyes. 
Weinreb et al [30] showed that reproducibility was improved when multiple scans were averaged into a single data set, recommending what is now the clinical practice of averaging three scans. The average standard deviation of all image elements was $35.5 \mathrm{~m}$ in healthy subjects, and averaging three scans reduced this measure to $25.7 \mathrm{~m}$. In patients with glaucoma, the standard deviation was $40.2 \mathrm{~m}$ with one scan, $28.5 \mathrm{~m}$ with three scans, and $24.1 \mathrm{~m}$ with five scans.

Measurements with the HRT in healthy volunteers and a model eye had less variability when compared with ONH analyzer measurements [29]. Another study showed a significant reduction in the interobserver and intraobserver variability using the HRT when compared with computer-assisted analysis of stereoscopic photographs of the optic disk [31].

Sihota et al [32] studied test-retest variability using the HRT II versus the first-generation HRT. Although they found similar values, eyes with uncorrected astigmatism of more than 1 diopter and poor visual acuity were suggested to have higher variability with the HRT II.

\section{Sources of error or variability}

Pupil dilation-Mikelberg et al [33] reported higher reproducibility for undilated pupils when compared with dilated pupils. Contradictory findings were reported by Zangwill et al [34]. In their study, dilation of the pupil did not change most HRT parameters; however, for images of poorer quality, the differences were more pronounced.

Contour line-The operator of the HRT must trace the margin of the ONH to obtain the stereometric analysis. Hatch et al [35] assessed the interobserver agreement of HRT parameters reflecting the variation in contour line placement. The interobserver agreement ranged from "substantial" (intraclass correlation coefficient [ICC], 0.67-0.73) for rim volume and disk area to "near perfect" (ICC, 0.83-0.94) for the mean height of contour and cup shape, suggesting that these parameters are less dependent on the contour line placement. Iester et al [36] devised a method using a computer program to create the topographic map, thereby avoiding the subjective observer's input by drawing the optic disk contour, and showed an increased capacity to differentiate normal from glaucomatous optic disks.

Reference plane-Many of the stereoscopic HRT measurements are strongly related to the location of the reference plane. Tan et al [37] showed that the positioning of the reference plane was the most significant contributor to the variability of measurements ( $\geq 95 \%$ of cases). In an effort to reduce the variation, Burk et al [38] suggested a method of creating a "flexible" reference plane accounting for the subject's particular optic disk shape when calculating the reference plane. Park and Caprioli [39] located the reference plane posterior to the contour line based on nerve fiber layer measurements as determined by OCT, and showed an improved diagnostic capability mainly in abnormal ONH configurations.

Blood vessels-In many cases, the HRT analyses incorporate blood vessels into the neuroretinal rim. This inclusion has been suggested as the reason for the higher HRT rim measurements when compared with the findings of optic disk photograph planimetric evaluation [40,41]. Moreover, the pulsations of the retinal arteries also cause variability in HRT measurements. Chauhan and McCormic [42] showed that pulse synchronization scanning resulted in a mean $13.6 \%$ decrease in image variability.

\section{Ability to distinguish normal from glaucomatous eyes}

A high correlation has been reported between HRT measurements and visual field global indexes [43-45]. Numerous studies have examined the capabilities of HRT in differentiating normal and glaucomatous eyes. Cup shape measure, rim area, and cup volume seem to be the 
best HRT parameters in discriminating between eyes, although considerable overlap exist between groups [46,47]. Improved discrimination between groups has been found by combining several parameters and ONH segmentation [48-53]. Two of these methods have been incorporated into the HRT II: Mikelberg's discriminating analysis and Moorfields regression analysis [50,51]. When these methods are used, the specificity and sensitivity to differentiate between normal subjects and patients with early glaucoma reach $78 \%$ and $89 \%$, respectively, with Mikelberg's discriminating analysis and $96.3 \%$ and $84.3 \%$, respectively, with Moorfields regression analysis [50,51]. Implementing more sophisticated mathematical approaches such as neural networks might provide further improvement [54].

The capability of the HRT to detect ONH glaucomatous changes before the appearance of a visual field defect was evaluated by Kamal et al [55] who examined a small group of ocular hypertensive individuals in whom reproducible visual field changes subsequently developed. Various parameters were found to be significantly different from those of normal subjects.

Chauhan et al [56] have described a new statistical technique for detecting changes in topography over time with HRT using an analysis of variance technique. When this technique is used, a higher frequency of progression is detected by the HRT when compared with visual field progression, which might suggest higher sensitivity of this method for longitudinal evaluation; however, the specificity remains uncertain [57].

\author{
Strengths and limitations \\ Strengths \\ - Rapid simple operation of the device (HRT II) \\ - Three-dimensional, topographic representation of the $\mathrm{ONH}$ \\ - No pupil dilation necessary \\ - Advanced data analysis capability built-in to machine
}

\title{
Limitations
}

- The use of a reference plane is required.

- Manual tracing of the ONH margin must be performed by the operator.

- Measurements may be affected by blood vessels.

- The CSLO method is appropriate for scanning the ONH only and may be affected by anatomic variation or pathologic processes. Although software exists for nerve fiber layer and macular analysis, the physical limitations of axial resolution for CSLO for these purposes preclude useful quantitative thickness measurements with this device in these areas.

\section{Scanning laser polarimetry}

\section{Device fundamentals}

Scanning laser polarimetry is an imaging technology optimized for quantitative measurements of the nerve fiber layer for the detection and evaluation of glaucoma. It uses the birefringent properties of the retinal nerve fiber layer to quantify its thickness. The parallel arrangement of the microtubules within the retinal ganglion cell axons causes a quantifiable change in the polarization of light that passes through them. This change is called retardation, and its numerical value is proportionate to the thickness of the nerve fiber layer [58]. 
Currently, SLP is in its fourth commercial generation (Nerve Fiber Analyzer [NFA], NFA II, GDx, GDx VCC; Laser Diagnostic Technologies, San Diego, California). The GDx device uses a diode laser (wavelength, $780 \mathrm{~nm}$ ) for the illumination and measurement of a $15 \times 15$ degree area of retina with an acquisition time of 0.7 seconds. Pupil dilation is not necessary, because studies have shown that changing the pupil size does not significantly affect SLP measurements [59,60]. Data from the scanned area are displayed as a $256 \times 256$ pixel colorcoded grid signifying different levels of retardation and nerve fiber layer thickness. The GDx provides numerous quantitative parameters, all of which are calculated from a band 10 pixels wide in an ellipse concentric to the ONH (Figs. 4-6).

In an early validation study, Weinreb et al [61] correlated the histopathologic findings in fixed monkey eyes with retardation measurements and demonstrated a good correlation $(r=0.83)$ between retardation and retinal nerve fiber layer thickness.

Because mainly the cornea and, to a lesser degree, the lens and the vitreous have birefringent properties in addition to those of the nerve fiber layer, a compensator accounting for these components has been incorporated into the GDx. Before the development of the current version of the GDx variable corneal compensator (VCC), the SLP device used a fixed compensator, assuming that all eyes had a slow axis of corneal birefringence of 15 degrees in the nasal and downward direction with a magnitude of $60 \mathrm{~nm}$. Studies by Greenfield et al [62] and Knighton et al [63] revealed a large variation in polarization properties of the cornea in different subjects. This variation should be compensated properly to obtain accurate nerve fiber layer measurements. This observation led to the development of the GDx VCC, which allows for customized compensation based on the individual corneal properties. The VCC uses the radial birefringence of Henle's fiber layer in the macula as a control for measurement of corneal birefringence. Based on these measurements, the VCC is adjusted for each eye.

Many of the studies conducted with the GDx must be re-evaluated using the GDx VCC before the utility of this technology can be evaluated in the diagnosis and management of glaucoma. The information presented in following section is discussed mainly in terms of its applicability to the GDx VCC system.

\section{Reproducibility}

Reproducibility data are sparse for the GDx VCC; however, it can be assumed that this device will demonstrate improved reproducibility when compared with the original GDx. Weinreb et al calculated the reproducibility of their early SLP system as the mean standard deviation of each pixel in the mean images. They found that the overall mean standard deviation was 1.0 degree [58]. Hoh et al [64] found an intraoperator COV for the NFA II device for nerve fiber layer thickness measurements of $4.5 \%$ and $4.9 \%$ for two operators, with decreased reproducibility between operators. Zangwill et al [65] reported a mean COV for interoperator reproducibility for the NFA II of $4.2 \%$. Hollo et al found the reproducibility to be comparable in normal and glaucoma groups, with a COV between $3 \%$ and $8.9 \%$ for the different sectors investigated [60]. Waldock et al [66] also reported high interoperator reproducibility of SLP retardation values and demonstrated improvement of reproducibility with the use of a blood vessel removal algorithm.

\section{Sources of error or variability}

Ethnicity and age-Ethnicity and age have an effect on retinal nerve fiber layer thickness measurements by SLP, and these population factors must be taken into consideration when interpreting results $[67,68]$. 
Corneal surgeries-Owing to the corneal birefringence properties, surgical procedures in the cornea (eg, laser-assisted in situ keratomileusis [LASIK], corneal transplantation) can induce erroneous measurements. The introduction of subject-specific corneal compensation is likely to resolve this source of variability.

Vitreous opacities-Pons et al [69] studied the effect of vitreous opacities on retardation measurements and showed that artifacts produced by these irregularities could falsely increase the value obtained for mean retinal nerve fiber layer thickness.

Motion artifacts-The possibility that motion of the eye during scanning could interfere with measurements was investigated by Colen and Lemij [70]. Motion artifacts led to an increase in retardation and affected several GDx parameters. This increase was shown to be highly variable, and caution was recommended when interpreting images with such artifacts.

Split nerve fiber layer bundles-The GDx images of the peripapillary nerve fiber layer allow the visualization of nerve fiber bundles. A study by Colen and Lemij showed that split nerve fiber layer bundles - areas in the GDx image where higher retardation is clearly divided into two symmetric-appearing parts-are a common SLP finding in healthy eyes, especially in the superior region [71]. It is likely that these areas will continue to be seen with the use of GDx VCC. This finding can be considered normal in patients who have glaucoma even though it can influence some of the built-in GDx parameters, such as the superior maximum or symmetry.

Macular pathologies-Bagga et al [72] noted that anterior chamber birefringence compensation in GDx VCC is based on measurements of the macula as an intraocular polarimeter and is highly dependent on an intact Henle's layer. This dependence might induce a source of error in measurement, especially in instances of macular structural disease.

\section{Ability to distinguish normal from glaucomatous eyes}

Numerous studies have assessed the ability of the GDx to distinguish normal from glaucomatous eyes [73-86]. Nevertheless, because of the inappropriate fixed corneal compensation in many cases using previous GDx versions, the estimates of the sensitivity and specificity of this diagnostic modality are of questionable utility.

In a study that compared the older fixed corneal compensator GDx system with the modified GDx VCC system, Weinreb et al [87] showed that the VCC device had an increased sensitivity and increased areas under the receiver operator characteristic (ROC) curve, a measure of the overall discriminating ability of a test that incorporates sensitivity and specificity. The areas under the ROC for the various GDx VCC parameters ranged from 0.75 to 0.83 versus 0.62 to 0.68 without the corneal compensation. Similar findings in other studies confirm that the GDx VCC device has a better correlation with visual function than the original GDx with fixed compensation [88,89]. Another study showed that adding individualized compensation to GDx scans allowed the investigators to obtain retardation maps that demonstrated defects that matched those observed in red-free fundus photographs, whereas scans with fixed compensation did not correlate [90].

One of the most promising GDx parameters in terms of identifying glaucomatous changes is a neural network product called "the number" [91-93]. Because this neural network was developed using GDx data, it cannot be applied to GDx VCC data. Studies are underway to determine the new number using GDx VCC data.

Medeiros et al [94] applied Fourier analysis to the retinal nerve fiber layer thickness GDx VCC measurements to improve the ability of this device to distinguish normal versus glaucomatous 
eyes. Applying the Fourier-based linear discriminant function gave a sensitivity of $84 \%$ for a given specificity of $92 \%$. This result was a significant improvement over the parameters given automatically by the device.

\author{
Strengths and limitations

\section{Strengths} \\ - Rapid simple operation of device \\ - $\quad$ No pupil dilation necessary
}

\title{
Limitations
}

- Limited data are available regarding the VCC system.

- The SLP-VCC method requires an internal reference polarimeter (macula region), which might be affected by macular pathologies.

- The SLP-VCC method can be used to scan the peripapillary region only and may be affected by anatomic variations or pathologic processes.

\section{Optical coherence tomography}

\section{Device fundamentals}

Optical coherence tomography is a noncontact noninvasive imaging technology that uses light to create high-resolution, real-time, cross-sectional tomographic images [95]. OCT is the optical equivalent of B-scan ultrasonography wherein light reflection from the scanned area is detected. The machine can differentiate layers in the retina owing to differences in the time delay of reflections from various components of the tissue.

The OCT device uses a light source consisting of a near-infrared, low-coherence superluminescent diode laser (wavelength, $850 \mathrm{~nm}$ ) split at a 50/50 coupler into two arms. One arm sends light to the actual sample, and the other sends light to a reference mirror. For the two beams to recombine, their pulses must arrive at nearly the same time. An interference signal is created when path lengths of the reference and measurement arms are closely matched to within the coherence length of the light. A series of these scans is created by panning the light source across the sample, which ultimately results in a two-dimensional, color-coded map based on detection of the previously described interference signals. The device can scan the macula, peripapillary, and ONH regions (see Fig. 1 and Figs. 7-11). The peripapillary scan is a circular scan optimally taken with a diameter of $3.4 \mathrm{~mm}$ centered at the ONH [96]. The macular and $\mathrm{ONH}$ scans are composed from six linear scans in a spoke pattern configuration equally spaced 30 degrees apart. The machine automatically identifies the $\mathrm{ONH}$ margin as the endings of the retinal pigment epithelium layer, eliminating the need for subjective definition of the margin by the operator. Although it has been recommended that the images be acquired after pupil dilation, satisfactory scans can be achieved in most cases without dilation.

Several generations of the commercial version of the OCT device (Carl Zeiss Meditec, Dublin, California) have been developed. The first-generation OCT 1 has transverse and axial resolutions of approximately $20 \mathrm{~m}$ and 10 to $15 \mathrm{~m}$, respectively. The second-generation OCT 2 has similar hardware with an improved user interface. Both generations acquire 100 vertical A-scans in a standard OCT scan in an acquisition time of approximately 1.2 seconds.

The recently released third-generation OCT 3 machine has improved axial resolution of 8 to 10 $\mathrm{m}$. The sampling densities can be selected by the user as 512, 256, or 128 vertical A-scans. 
An experimental ultrahigh-resolution OCT system has been developed using a Ti: $\mathrm{Al}_{2} \mathrm{O}_{3}$ laser that provides an improved axial resolution of 2 to $3 \mathrm{~m}$ [97]. This resolution makes it possible to identify otherwise unseen intermediate retinal layers, such as the retinal ganglion cell layer.

\section{Reproducibility}

Several studies have confirmed the high reproducibility of OCT measurements [96,98-102]. Using a prototype OCT device, Schuman et al found that the standard deviation of nerve fiber layer thickness measurements was 10 to $20 \mathrm{~m}$ for the mean overall and 15 to $30 \mathrm{~m}$ for clockhour measurements [96]. Jones et al [103] calculated the mean COVs for retinal nerve fiber layer data for global thickness, quadrant measurements, and 12-segment subdivisions and found them to be 5\%,8\%, and 9\%, respectively. Carpineto et al [104] showed reproducible nerve fiber layer thickness measurements in normal and glaucomatous eyes using various circumpapillary scan radii and attributed the greatest variability to intersubject differences. Other investigators have shown that the reproducibility of OCT measurements is significantly increased with increased sampling density [105].

\section{Sources of error or variability}

Age-From the earliest studies with OCT [106] to more recent studies [107,108], it has been shown that nerve fiber layer thickness decreases with age; therefore, it has been suggested that the OCT normative values should be developed in a manner that is adjusted for this aging effect.

Sampling density-Although OCT offers the highest axial resolution available for ophthalmic imaging, the transverse sampling density is limited in all three scan regions. Using the OCT 1 and 2 devices, nerve fiber layer measurements are made by scanning a 360-degree peripapillary region, but the circle is sampled for only 100 data points ( 25 points per quadrant) along this path. Gurses-Ozden et al have shown that increasing sampling density along this path (to 100 points per quadrant) decreases variability in nerve fiber layer thickness measurements [105]. Other investigators studying the reproducibility of OCT measurements have also suggested the limited number of sampling points as a source of measurement variability [98]. The OCT 3 device allows the user to select up to 512 sampling points, which is likely to address this issue. Furthermore, as described previously, the macular and $\mathrm{ONH}$ scans are composed of linear scans in a spoke pattern configuration with interpolation of the data for the areas between scans. It is likely that the unscanned areas between the linear spokes and the unsampled points along each spoke also contribute to variation in OCT measurements [109].

\section{Ability to distinguish normal from glaucomatous eyes}

Numerous studies have evaluated the capability of OCT measurements to distinguish between normal and glaucomatous eyes. Schuman et al showed that OCT nerve fiber layer measurements were significantly thinner in glaucomatous eyes when compared with normal eyes [106]. This observation was confirmed by Bowd et al [110] who found that the mean overall nerve fiber layer and the layer in quadrants were thinner in glaucomatous versus normal and ocular hypertensive eyes. Soliman et al [111] showed that retinal nerve fiber layer measurements on OCT had a higher diagnostic accuracy when compared with standard redfree photographic evaluation of glaucomatous eyes. Bowd et al found that the largest area under the ROC curve for distinguishing between normal and early glaucomatous eyes was for OCT inferior quadrant thickness (0.91) [78].

Recent studies have investigated the OCT macular and ONH capabilities in differentiating between groups. Greenfield et al [112] found a significant correlation between macular thickness and global visual field indexes. Guedes et al reported a significant reduction in 
macular thickness in glaucoma-affected eyes when compared with normal eyes. The area under the ROC curve for discriminating between normal and advanced glaucomatous eyes was 0.80 in this study. A higher area under the ROC curve was found in the same study for circumpapillary nerve fiber layer measurements [109]. Lederer et al [113] used retinal macular volume to demonstrate a significant difference between normal and early glaucomatous eyes. Schuman et al [114] found that OCT analysis of the ONH provided useful parameters for differentiating between groups, with an area under the ROC curve of 0.79 .

A recent study by Essock et al [115] showed that by applying Fourier-based linear discriminant analysis to OCT nerve fiber layer data (OCT 2), an increased area under the ROC curve could be demonstrated (0.92) when compared with the results using other parameters such as mean nerve fiber layer thickness $(0.87)$ or inferior thickness $(0.89)$.

\author{
Strengths and limitations \\ Strengths \\ - Provides a cross-sectional view of examined tissue \\ - Highest axial resolution \\ - Multiple scanning regions \\ - Automatic definition of $\mathrm{ONH}$ margin
}

\title{
Limitations
}

- $\quad$ Limited transverse sampling

\section{Retinal thickness analyzer}

\section{Device fundamentals}

Use of the RTA is similar to slit lamp biomicroscopy as it projects a thin laser slit obliquely onto the retina. Owing to the oblique projection, the back-reflected light contains two light peaks corresponding to the vitreoretinal interface and the chorioretinal interface. The distance between these layers reflects the retinal thickness [116,117]. The commercial version of this technology (Talia Technology, Neve Ilan, Israel) uses a green HeNe laser $(540 \mathrm{~nm})$ that, when projected onto the fundus, is $3 \mathrm{~mm}$ in length and approximately $10 \mathrm{~m}$ in width. The RTA acquires 16 optical cross-sections approximately $100 \mathrm{~m}$ apart, covering a total area of $3 \times 3$ $\mathrm{mm}$ in $400 \mathrm{msec}$. Five of these scans are obtained for coverage of $20 \times 20$ degrees $(6 \times 6 \mathrm{~mm})$ around the fovea using internal fixation targets to direct the eye to the proper position for each scan. Similarly, four scans are acquired for imaging of the peripapillary region and four scans for the $\mathrm{ONH}$. The total acquisition time for the 13 scans is approximately 10 minutes. The axial length and refractive error of the examined eye are measured for automatic calibration of the measured thickness. Because the incoming light is projected at an angle and the outgoing light is distant from the incoming light at the pupil level, pupil dilation of no less than $5 \mathrm{~mm}$ is required for obtaining images.

Zeimer et al reported that the depth precision of the device - the ability to determine accurately the location of a single interface-was 5 to $10 \mathrm{~m}$. The depth resolution of the device-the minimal distance between two surfaces that can be resolved by the device-was $50 \mathrm{~m} \mathrm{[117].}$

\section{Reproducibility}

Zeimer et al used a prototype instrument and demonstrated good reproducibility, with a standard deviation for the measured data of $\pm 9 \mathrm{~m}$ for in vitro measurements [116]. In a later in vivo study, they showed an intravisit COV of $3.6 \%$ (11.5 m), a single-scan intervisit 
reproducibility of $4.1 \%(13.1 \mathrm{~m})$, and a three-scan average intervisit reproducibility of $3.2 \%$ $(10.2 \mathrm{~m})$ [117]. Other studies have found that the RTA reproducibly measures foveal thickness and demonstrates high interexaminer reproducibility $[100,118,119]$.

\title{
Sources of error or variability
}

Media opacities-The RTA is particularly susceptible to media opacities. In a study by Polito et al [120], a large number of RTA measurements were unusable secondary to interference from media opacities.

Focusing images-In a study of foveal thickness measurements in patients with normal and edematous retinas, Neubauer et al compared RTA measurements with OCT measurements. Although measurements using the RTA were reproducible, they were relatively higher when compared with OCT measurements [118]. The investigators suggested that the overestimation might be related to "fuzzy" images despite adequate focusing according to the user manual.

\section{Ability to distinguish normal from glaucomatous eyes}

In a pilot study by Zeimer et al [121], quantitative retinal thickness losses were detected in the posterior pole of patients who had glaucoma.

\author{
Strengths and limitations \\ Strengths \\ - Multiple scanning regions \\ - Limited cross-sectional view
}

\section{Limitations}

- Pupil dilation required

- Highly affected by media opacities

\section{Studies involving multiple imaging technologies}

\section{Confocal scanning laser ophthalmoscopy and optical coherence tomography}

Device agreement-Mistlberger et al [122] compared OCT measurements with HRT topographic parameters and found a significant correlation between mean OCT nerve fiber layer thickness measurements and five HRT parameters: rim area, cup-disk ratio, cup shape measure, nerve fiber layer thickness, and nerve fiber layer cross-sectional area $(P<0.02)$. Schuman et al looked at the relationship of HRT and OCT with respect to ONH measurements [114]. HRT and OCT measurements of disk area, cup-disk ratio, cup area, and cup volume were highly correlated $(r=0.75-0.85, P<0.0001)$, whereas the rim volume was moderately correlated $(r=0.54, P<0.0001)$.

Sensitivity and specificity comparisons-In a comparative cross-sectional study by Sanchez Galeana et al, HRT optic disk scans and OCT nerve fiber layer analysis were compared to determine their sensitivity and specificity in discriminating normal versus early to moderate glaucomatous eyes [82]. HRT sensitivity ranged from $64 \%$ to $75 \%$ for the various parameters, and specificity ranged from $68 \%$ to $80 \%$. OCT achieved a sensitivity between $76 \%$ and $79 \%$ and a specificity of $68 \%$ to $81 \%$. Zangwill et al compared the ability of HRT and OCT to distinguish normal and glaucomatous eyes using area under the ROC curves and found no significant differences between the best discriminating parameter from each instrument [83]. Schuman et al reported areas under the ROC curve for an association with clinical diagnosis 
among OCT and HRT measurements of the ONH [114]. The two devices demonstrated similar performances, with an area under the ROC ranging from 0.47 to 0.79 for the various parameters.

\section{Optical coherence tomography and scanning laser polarimetry}

Device agreement-A recent study by Bagga et al demonstrated a significant correlation between several SLP (GDx VCC) parameters and OCT-derived nerve fiber layer thickness measurements [89]. This correspondence was shown to be stronger with VCC than with the fixed compensation model.

\section{Optical coherence tomography and retinal thickness analysis}

Device agreement-Polito et al [21] reported excellent agreements between OCT and RTA measurements of foveal retinal thickness, although they found that media opacities created less interference in OCT images than in RTA. In contrast, another study showed that RTA measurements of foveal thickness differed from OCT measurements in that they were consistently higher, a finding attributed to the different definition of the measured thickness between the two devices [118].

\section{Summary}

Structural assessment using the imaging technologies discussed herein provides reproducible quantitative measurements of posterior segment ocular structures. These measurements have been found to provide useful data for glaucoma detection in various regions of the posterior segment. Further studies are needed to evaluate the utility of these technologies for preperimetric glaucoma detection and for monitoring glaucoma progression over an extended period.

\section{References}

1. Leske MC, Heijl A, Hussein M, et al. Factors for glaucoma progression and the effect of treatment: the early manifest glaucoma trial. Arch Ophthalmol 2003;121(1):48-56. [PubMed: 12523884]

2. Goldberg I. Relationship between intraocular pressure and preservation of visual field in glaucoma. Surv Ophthalmol 2003;48:S3-7. [PubMed: 12852428]

3. The Advanced Glaucoma Intervention Study (AGIS); The AGIS Investigators. 7. The relationship between control of intraocular pressure and visual field deterioration. Am J Ophthalmol 2000;130(4): 429-40. [PubMed: 11024415]

4. Lichter PR. Variability of expert observers in evaluating the optic disc. Trans Am Ophthalmol Soc 1976;74:532-72. [PubMed: 867638]

5. Gaasterland DE, Blackwell B, Dally LG, et al. The Advanced Glaucoma Intervention Study (AGIS): 10. Variability among academic glaucoma subspecialists in assessing optic disc notching. Trans Am Ophthalmol Soc 2001;99:177-84. [PubMed: 11797305]

6. Burnstein Y, Ellish NJ, Magbalon M, Higginbotham EJ. Comparison of frequency doubling perimetry with Humphrey visual field analysis in a glaucoma practice. Am J Ophthalmol 2000;129(3):328-33. [PubMed: 10704548]

7. Sekhar GC, Naduvilath TJ, Lakkai M, et al. Sensitivity of Swedish interactive threshold algorithm compared with standard full threshold algorithm in Humphrey visual field testing. Ophthalmology 2000;107(7):1303-8. [PubMed: 10889102]

8. Wadood AC, Azuara-Blanco A, Aspinall P, et al. Sensitivity and specificity of frequency-doubling technology, tendency-oriented perimetry, and Humphrey Swedish interactive threshold algorithm-fast perimetry in a glaucoma practice. Am J Ophthalmol 2002;133(3):327-32. [PubMed: 11860968]

9. Johnson CA, Sample PA, Cioffi GA, et al. Structure and function evaluation (SAFE). I. Criteria for glaucomatous visual field loss using standard automated perimetry (SAP) and short wavelength automated perimetry (SWAP). Am J Ophthalmol 2002;134(2):177-85. [PubMed: 12140023] 
10. Keltner JL, Johnson CA, Quigg JM, et al. Confirmation of visual field abnormalities in the Ocular Hypertension Treatment Study. Ocular Hypertension Treatment Study Group. Arch Ophthalmol 2000;118(9):1187-94. [PubMed: 10980763]

11. Sommer A, Pollack I, Maumenee AE. Optic disc parameters and onset of glaucomatous field loss. I. Methods and progressive changes in disc morphology. Arch Ophthalmol 1979;97(8):1444-8. [PubMed: 464866]

12. Pederson J, Anderson D. The mode of progressive disc cupping in ocular hypertension and glaucoma. Arch Ophthalmol 1980;98:490-5. [PubMed: 7362506]

13. Quigley HA, Katz J, Derick RJ, et al. An evaluation of optic disc and nerve fiber layer examinations in monitoring progression of early glaucoma damage. Ophthalmology 1992;99(1):19-28. [PubMed: 1741133]

14. Sommer A, Miller NR, Pollack I, et al. The nerve fiber layer in the diagnosis of glaucoma. Arch Ophthalmol 1977;95(12):2149-56. [PubMed: 588106]

15. Sommer A, Quigley HA, Robin AL, et al. Evaluation of nerve fiber layer assessment. Arch Ophthalmol 1984;102(12):1766-71. [PubMed: 6508617]

16. Sommer A, Katz J, Quigley HA, et al. Clinically detectable nerve fiber atrophy precedes the onset of glaucomatous field loss. Arch Ophthalmol 1991;109(1):77-83. [PubMed: 1987954]

17. Quigley HA, Addicks EM, Green WR. Optic nerve damage in human glaucoma. III. Quantitative correlation of nerve fiber loss and visual field defect in glaucoma, ischemic neuropathy, papilledema, and toxic neuropathy. Arch Ophthalmol 1982;100(1):135-46. [PubMed: 7055464]

18. Hattenhauer MG, Johnson DH, Ing HH, et al. The probability of blindness from open-angle glaucoma. Ophthalmology 1998;105(11):2099-104. [PubMed: 9818612]

19. Chen PP. Blindness in patients with treated open-angle glaucoma. Ophthalmology 2003;110(4):72633. [PubMed: 12689894]

20. Oliver JE, Hattenhauer MG, Herman D, et al. Blindness and glaucoma: a comparison of patients progressing to blindness from glaucoma with patients maintaining vision. Am J Ophthalmol 2002;133 (6):764-72. [PubMed: 12036667]

21. Polito A, Shah SM, Haller JA, et al. Comparison between retinal thickness analyzer and optical coherence tomography for assessment of foveal thickness in eyes with macular disease. Am J Ophthalmol 2002;134(2):240-51. [PubMed: 12140031]

22. Master, B.; Kino, G. Confocal microscopy of the eye. In: Masters, BR., editor. Noninvasive diagnostic techniques in ophthalmology. New York: Springer-Verlag; 1990.

23. Shuman H, Murray J, DiLullo C. Confocal microscopy: an overview. Biotechniques 1989;7:154-63. [PubMed: 2517017]

24. Kruse FE, Burk RO, Volcker HE, et al. Reproducibility of topographic measurements of the optic nerve head with laser tomographic scanning. Ophthalmology 1989;96(9):1320-4. [PubMed: 2780001]

25. Dreher AW, Tso PC, Weinreb RN. Reproducibility of topographic measurements of the normal and glaucomatous optic nerve head with the laser tomographic scanner. Am J Ophthalmol 1991;111(2): 221-9. [PubMed: 1992744]

26. Rohrschneider K, Burk RO, Kruse FE, Volcker HE. Reproducibility of the optic nerve head topography with a new laser tomographic scanning device. Ophthalmology 1994;101(6):1044-9. [PubMed: 8008345]

27. Rohrschneider K, Burk RO, Volcker HE. Reproducibility of topometric data acquisition in normal and glaucomatous optic nerve heads with the laser tomographic scanner. Graefes Arch Clin Exp Ophthalmol 1993;231(8):457-64. [PubMed: 8224945]

28. Chauhan BC, LeBlanc RP, McCormick TA, Rogers JB. Test-retest variability of topographic measurements with confocal scanning laser tomography in patients with glaucoma and control subjects. Am J Ophthalmol 1994;118(1):9-15. [PubMed: 8023882]

29. Janknecht P, Funk J. Optic nerve head analyser and Heidelberg retina tomograph: accuracy and reproducibility of topographic measurements in a model eye and in volunteers. Br J Ophthalmol 1994;78(10):760-8. [PubMed: 7803352]

30. Weinreb RN, Lusky M, Bartsch DU, Morsman D. Effect of repetitive imaging on topographic measurements of the optic nerve head. Arch Ophthalmol 1993;111(5):636-8. [PubMed: 8489444] 
31. Garway-Heath DF, Poinoosawmy D, Wollstein G, et al. Inter- and intraobserver variation in the analysis of optic disc images: comparison of the Heidelberg retina tomograph and computer assisted planimetry. Br J Ophthalmol 1999;83(6):664-9. [PubMed: 10340972]

32. Sihota R, Gulati V, Agarwal HC, et al. Variables affecting test-retest variability of Heidelberg Retina Tomograph II stereometric parameters. J Glaucoma 2002;11(4):321-8. [PubMed: 12169969]

33. Mikelberg F, Wijsman K, Schulzer M. Reproducibility of topographic parameters obtained with Heidelberg Retina Tomograph. J Glaucoma 1993;2:101-3.

34. Zangwill LM, Berry CC, Weinreb RN. Optic disc topographic measurements after pupil dilation. Ophthalmology 1999;106(9):1751-5. [PubMed: 10485546]

35. Hatch WV, Flanagan JG, Williams-Lyn DE, et al. Interobserver agreement of Heidelberg retina tomograph parameters. J Glaucoma 1999;8(4):232-7. [PubMed: 10464730]

36. Iester M, De Ferrari R, Zanini M. Topographic analysis to discriminate glaucomatous from normal optic nerve heads with a confocal scanning laser: new optic disk analysis without any observer input. Surv Ophthalmol 1999;44:S33-40. [PubMed: 10548115]

37. Tan JC, Garway-Heath DF, Fitzke FW, Hitchings RA. Reasons for rim area variability in scanning laser tomography. Invest Ophthalmol Vis Sci 2003;44(3):1126-31. [PubMed: 12601039]

38. Burk RO, Vihanninjoki K, Bartke T, et al. Development of the standard reference plane for the Heidelberg retina tomograph. Graefes Arch Clin Exp Ophthalmol 2000;238(5):375-84. [PubMed: 10901468]

39. Park KH, Caprioli J. Development of a novel reference plane for the Heidelberg retina tomograph with optical coherence tomography measurements. J Glaucoma 2002;11(5):385-91. [PubMed: 12362076]

40. Jonas JB, Mardin CY, Grundler AE. Comparison of measurements of neuroretinal rim area between confocal laser scanning tomography and planimetry of photographs. Br J Ophthalmol 1998;82(4): 362-6. [PubMed: 9640181]

41. Dichtl A, Jonas JB, Mardin CY. Comparison between tomographic scanning evaluation and photographic measurement of the neuroretinal rim. Am J Ophthalmol 1996;121(5):494-501. [PubMed: 8610792]

42. Chauhan BC, McCormick TA. Effect of the cardiac cycle on topographic measurements using confocal scanning laser tomography. Graefes Arch Clin Exp Ophthalmol 1995;233:568-72. [PubMed: 8543208]

43. Brigatti L, Caprioli J. Correlation of visual field with scanning confocal laser optic disc measurements in glaucoma. Arch Ophthalmol 1995;113(9):1191-4. [PubMed: 7661755]

44. Iester M, Mikelberg FS, Courtright P, Drance SM. Correlation between the visual field indices and Heidelberg retina tomograph parameters. J Glaucoma 1997;6(2):78-82. [PubMed: 9098814]

45. Eid TM, Spaeth GL, Katz LJ, et al. Quantitative estimation of retinal nerve fiber layer height in glaucoma and the relationship with optic nerve head topography and visual field. J Glaucoma 1997;6 (4):221-30. [PubMed: 9264301]

46. Hatch WV, Flanagan JG, Etchells EE, et al. Laser scanning tomography of the optic nerve head in ocular hypertension and glaucoma. Br J Ophthalmol 1997;81(10):871-6. [PubMed: 9486029]

47. Iester M, Broadway DC, Mikelberg FS, Drance SM. A comparison of healthy, ocular hypertensive, and glaucomatous optic disc topographic parameters. J Glaucoma 1997;6(6):363-70. [PubMed: 9407364]

48. Iester M, Mikelberg FS, Drance SM. The effect of optic disc size on diagnostic precision with the Heidelberg retina tomograph. Ophthalmology 1997;104(3):545-8. [PubMed: 9082287]

49. Bathija R, Zangwill L, Berry CC, et al. Detection of early glaucomatous structural damage with confocal scanning laser tomography. J Glaucoma 1998;7(2):121-7. [PubMed: 9559499]

50. Mikelberg FS, Parfitt CM, Swindale NV. Ability of the Heidelberg Retina Tomograph to detect early glaucomatous visual field loss. J Glaucoma 1996;4:242-7.

51. Wollstein G, Garway-Heath DF, Hitchings RA. Identification of early glaucoma cases with the scanning laser ophthalmoscope. Ophthalmology 1998;105(8):1557-63. [PubMed: 9709774]

52. Miglior S, Guareschi M, Albe E, et al. Detection of glaucomatous visual field changes using the Moorfields regression analysis of the Heidelberg retina tomograph. Am J Ophthalmol 2003;136(1): 26-33. [PubMed: 12834666] 
53. Ford BA, Artes PH, McCormick TA, et al. Comparison of data analysis tools for detection of glaucoma with the Heidelberg Retina Tomograph. Ophthalmology 2003;110(6):1145-50. [PubMed: 12799239]

54. Bowd C, Chan K, Zangwill LM, et al. Comparing neural networks and linear discriminant functions for glaucoma detection using confocal scanning laser ophthalmoscopy of the optic disc. Invest Ophthalmol Vis Sci 2002;43(11):3444-54. [PubMed: 12407155]

55. Kamal DS, Viswanathan AC, Garway-Heath DF, et al. Detection of optic disc change with the Heidelberg retina tomograph before confirmed visual field change in ocular hypertensives converting to early glaucoma. Br J Ophthalmol 1999;83(3):290-4. [PubMed: 10365035]

56. Chauhan BC, Blanchard JW, Hamilton DC, LeBlanc RP. Technique for detecting serial topographic changes in the optic disc and peripapillary retina using scanning laser tomography. Invest Ophthalmol Vis Sci 2000;41(3):775-82. [PubMed: 10711693]

57. Chauhan BC, McCormick TA, Nicolela MT, LeBlanc RP. Optic disc and visual field changes in a prospective longitudinal study of patients with glaucoma: comparison of scanning laser tomography with conventional perimetry and optic disc photography. Arch Ophthalmol 2001;119(10):1492-9. [PubMed: 11594950]

58. Weinreb RN, Shakiba S, Zangwill L. Scanning laser polarimetry to measure the nerve fiber layer of normal and glaucomatous eyes. Am J Ophthalmol 1995;119(5):627-36. [PubMed: 7733188]

59. Hoh S, Greenfield D, Liebmann J, et al. Effect of pupillary dilation on retinal nerve fiber layer thickness measured by scanning laser polarimetry in eyes with and without cataract. J Glaucoma 1999;8:159-63. [PubMed: 10376254]

60. Hollo G, Suveges I, Nagymihaly A, Vargha P. Scanning laser polarimetry of the retinal nerve fibre layer in primary open angle and capsular glaucoma. Br J Ophthalmol 1997;81(10):857-61. [PubMed: 9486026]

61. Weinreb R, Dreher AW, Coleman A, et al. Histopathologic validation of Fourier-ellipsometry measurements of retinal nerve fiber layer thickness. Arch Ophthalmol 1990;108:557-60. [PubMed: 2322159]

62. Greenfield D, Knighton RW, Huang X. Effect of corneal polarization axis on assessment of retinal nerve fiber layer thickness by scanning laser polarimetry. Am J Ophthalmol 2000;129:715-22. [PubMed: 10926978]

63. Knighton RW, Huang X. Linear birefringence of the central human cornea. Invest Ophthalmol Vis Sci 2002;43:82-6. [PubMed: 11773016]

64. Hoh ST, Ishikawa H, Greenfield DS. Peripapillary nerve fiber layer thickness measurement reproducibility using scanning laser polarimetry. J Glaucoma 1998;7:12-5. [PubMed: 9493109]

65. Zangwill L, Berry CA, Garden VS, Weinreb RN. Reproducibility of retardation measurements with the nerve fiber analyzer II. J Glaucoma 1997;6:384-9. [PubMed: 9407367]

66. Waldock A, Potts MJ, Sparrow JM, Karwatowski WS. Clinical evaluation of scanning laser polarimetry. I. Intraoperator reproducibility and design of a blood vessel removal algorithm. Br J Ophthalmol 1998;82(3):252-9. [PubMed: 9602621]

67. Poinoosawmy D, Fontana L, Wu J, et al. Variation of nerve fibre layer thickness measurements with age and ethnicity by scanning laser polarimetry. Br J Ophthalmol 1997;81:350-4. [PubMed: 9227197]

68. Tjon-Fo-sang M, Lemij H. Retinal nerve fiber layer measurements in normal black subjects as determined with scanning laser polarimetry. Ophthalmology 1998;105:78-81. [PubMed: 9442781]

69. Pons ME, Rothman RF, Ozden RG, et al. Vitreous opacities affect scanning laser polarimetry measurements. Am J Ophthalmol 2001;131(4):511-3. [PubMed: 11292421]

70. Colen TP, Lemij HG. Motion artifacts in scanning laser polarimetry. Ophthalmology 2002;109(8): 1568-72. [PubMed: 12153812]

71. Colen TP, Lemij HG. Prevalence of split nerve fiber layer bundles in healthy eyes imaged with scanning laser polarimetry. Ophthalmology 2001;108(1):151-6. [PubMed: 11150281]

72. Bagga H, Greenfield DS, Knighton RW. Scanning laser polarimetry with variable corneal compensation: identification and correction for corneal birefringence in eyes with macular disease. Invest Ophthalmol Vis Sci 2003;44(5):1969-76. [PubMed: 12714631] 
73. Xu L, Chen PP, Chen YY, et al. Quantitative nerve fiber layer measurement using scanning laser polarimetry and modulation parameters in the detection of glaucoma. J Glaucoma 1998;7(4):270-7. [PubMed: 9713786]

74. Horn FK, Jonas JB, Martus P, et al. Polarimetric measurement of retinal nerve fiber layer thickness in glaucoma diagnosis. J Glaucoma 1999;8(6):353-62. [PubMed: 10604293]

75. Kogure S, Iijima H, Tsukahara S. A new parameter for assessing the thickness of the retinal nerve fiber layer for glaucoma diagnosis. Eur J Ophthalmol 1999;9(2):93-8. [PubMed: 10435420]

76. Essock EA, Sinai MJ, Fechtner RD, et al. Fourier analysis of nerve fiber layer measurements from scanning laser polarimetry in glaucoma: emphasizing shape characteristics of the 'double-hump' pattern. J Glaucoma 2000;9(6):444-52. [PubMed: 11131750]

77. Hoh ST, Greenfield DS, Mistlberger A, et al. Optical coherence tomography and scanning laser polarimetry in normal, ocular hypertensive, and glaucomatous eyes. Am J Ophthalmol 2000;129(2): 129-35. [PubMed: 10682963]

78. Bowd C, Zangwill LM, Berry CC, et al. Detecting early glaucoma by assessment of retinal nerve fiber layer thickness and visual function. Invest Ophthalmol Vis Sci 2001;42(9):1993-2003. [PubMed: 11481263]

79. Sinai MJ, Essock EA, Fechtner RD, Srinivasan N. Diffuse and localized nerve fiber layer loss measured with a scanning laser polarimeter: sensitivity and specificity of detecting glaucoma. J Glaucoma 2000;9(2):154-62. [PubMed: 10782625]

80. Choplin NT, Lundy DC. The sensitivity and specificity of scanning laser polarimetry in the detection of glaucoma in a clinical setting. Ophthalmology 2001;108(5):899-904. [PubMed: 11320020]

81. Poinoosawmy D, Tan JC, Bunce C, Hitchings RA. The ability of the GDx nerve fibre analyser neural network to diagnose glaucoma. Graefes Arch Clin Exp Ophthalmol 2001;239(2):122-7. [PubMed: 11372541]

82. Sanchez-Galeana C, Bowd C, Blumenthal EZ, et al. Using optical imaging summary data to detect glaucoma. Ophthalmology 2001;108(10):1812-8. [PubMed: 11581054]

83. Zangwill LM, Bowd C, Berry CC, et al. Discriminating between normal and glaucomatous eyes using the Heidelberg Retina Tomograph, GDx Nerve Fiber Analyzer, and Optical Coherence Tomograph. Arch Ophthalmol 2001;119(7):985-93. [PubMed: 11448320]

84. Bozkurt B, Irkec M, Karaagaoglu E, Orhan M. Scanning laser polarimetric analysis of retinal nerve fiber layer thickness in Turkish patients with glaucoma and ocular hypertension. Eur J Ophthalmol 2002;12(5):406-12. [PubMed: 12474924]

85. Funaki S, Shirakashi M, Yaoeda K, et al. Specificity and sensitivity of glaucoma detection in the Japanese population using scanning laser polarimetry. Br J Ophthalmol 2002;86(1):70-4. [PubMed: 11801507]

86. Greaney MJ, Hoffman DC, Garway-Heath DF, et al. Comparison of optic nerve imaging methods to distinguish normal eyes from those with glaucoma. Invest Ophthalmol Vis Sci 2002;43(1):140-5. [PubMed: 11773024]

87. Weinreb RN, Bowd C, Zangwill LM. Glaucoma detection using scanning laser polarimetry with variable corneal polarization compensation. Arch Ophthalmol 2003;121(2):218-24. [PubMed: 12583788]

88. Bowd C, Zangwill LM, Weinreb RN. Association between scanning laser polarimetry measurements using variable corneal polarization compensation and visual field sensitivity in glaucomatous eyes. Arch Ophthalmol 2003;121(7):961-6. [PubMed: 12860798]

89. Bagga H, Greenfield DS, Feuer W, Knighton RW. Scanning laser polarimetry with variable corneal compensation and optical coherence tomography in normal and glaucomatous eyes. Am J Ophthalmol 2003;135(4):521-9. [PubMed: 12654370]

90. Reus NJ, Colen TP, Lemij HG. Visualization of localized retinal nerve fiber layer defects with the GDx with individualized and with fixed compensation of anterior segment birefringence. Ophthalmology 2003;110(8):1512-6. [PubMed: 12917165]

91. Colen TP, Lemij HG. Sensitivity and specificity of the GDx: clinical judgment of standard printouts versus the number. J Glaucoma 2003;12(2):129-33. [PubMed: 12671467] 
92. Nguyen NX, Horn FK, Hayler J, et al. Retinal nerve fiber layer measurements using laser scanning polarimetry in different stages of glaucomatous optic nerve damage. Graefes Arch Clin Exp Ophthalmol 2002;240(8):608-14. [PubMed: 12192453]

93. Lauande-Pimentel R, Carvalho RA, Oliveira HC, et al. Discrimination between normal and glaucomatous eyes with visual field and scanning laser polarimetry measurements. Br J Ophthalmol 2001;85(5):586-91. [PubMed: 11316722]

94. Medeiros FA, Zangwill LM, Bowd C, et al. Fourier analysis of scanning laser polarimetry measurements with variable corneal compensation in glaucoma. Invest Ophthalmol Vis Sci 2003;44 (6):2606-12. [PubMed: 12766063]

95. Huang D, Swanson EA, Lin CP, et al. Optical coherence tomography. Science 1991;254(5035):117881. [PubMed: 1957169]

96. Schuman JS, Pedut-Kloizman T, Hertzmark E, et al. Reproducibility of nerve fiber layer thickness measurements using optical coherence tomography. Ophthalmology 1996;103(11):1889-98. [PubMed: 8942887]

97. Drexler W, Morgner U, Ghanta RK, et al. Ultrahigh-resolution ophthalmic optical coherence tomography. Nat Med 2001;7(4):502-7. [PubMed: 11283681]

98. Blumenthal EZ, Williams JM, Weinreb RN, et al. Reproducibility of nerve fiber layer thickness measurements by use of optical coherence tomography. Ophthalmology 2000;107(12):2278-82. [PubMed: 11097610]

99. Koozekanani D, Roberts C, Katz SE, Herderick EE. Intersession repeatability of macular thickness measurements with the Humphrey 2000 OCT. Invest Ophthalmol Vis Sci 2000;41(6):1486-91. [PubMed: 10798667]

100. Konno S, Akiba J, Yoshida A. Retinal thickness measurements with optical coherence tomography and the scanning retinal thickness analyzer. Retina 2001;21(1):57-61. [PubMed: 11217931]

101. Massin P, Vicaut E, Haouchine B, et al. Reproducibility of retinal mapping using optical coherence tomography. Arch Ophthalmol 2001;119(8):1135-42. [PubMed: 11483079]

102. Muscat S, Parks S, Kemp E, Keating D. Repeatability and reproducibility of macular thickness measurements with the Humphrey OCT system. Invest Ophthalmol Vis Sci 2002;43(2):490-5. [PubMed: 11818395]

103. Jones AL, Sheen NJ, North RV, Morgan JE. The Humphrey optical coherence tomography scanner: quantitative analysis and reproducibility study of the normal human retinal nerve fibre layer. Br J Ophthalmol 2001;85(6):673-7. [PubMed: 11371486]

104. Carpineto P, Ciancaglini M, Zuppardi E, et al. Reliability of nerve fiber layer thickness measurements using optical coherence tomography in normal and glaucomatous eyes. Ophthalmology 2003;110 (1):190-5. [PubMed: 12511365]

105. Gurses-Ozden R, Ishikawa H, Hoh ST, et al. Increasing sampling density improves reproducibility of optical coherence tomography measurements. J Glaucoma 1999;8(4):238-41. [PubMed: 10464731]

106. Schuman JS, Hee MR, Puliafito CA, et al. Quantification of nerve fiber layer thickness in normal and glaucomatous eyes using optical coherence tomography. Arch Ophthalmol 1995;113(5):58696. [PubMed: 7748128]

107. Mok KH, Lee VW, So KF. Retinal nerve fiber layer measurement of the Hong Kong Chinese population by optical coherence tomography. J Glaucoma 2002;11(6):481-3. [PubMed: 12483090]

108. Varma R, Bazzaz S, Lai M. Optical tomography-measured retinal nerve fiber layer thickness in normal Latinos. Invest Ophthalmol Vis Sci 2003;44(8):3369-73. [PubMed: 12882783]

109. Guedes V, Schuman JS, Hertzmark E, et al. Optical coherence tomography measurement of macular and nerve fiber layer thickness in normal and glaucomatous human eyes. Ophthalmology 2003;110 (1):177-89. [PubMed: 12511364]

110. Bowd C, Weinreb RN, Williams JM, Zangwill LM. The retinal nerve fiber layer thickness in ocular hypertensive, normal, and glaucomatous eyes with optical coherence tomography. Arch Ophthalmol 2000;118(1):22-6. [PubMed: 10636409]

111. Soliman MA, Van Den Berg TJ, Ismaeil AA, et al. Retinal nerve fiber layer analysis: relationship between optical coherence tomography and red-free photography. Am J Ophthalmol 2002;133(2): 187-95. [PubMed: 11812421] 
112. Greenfield DS, Bagga H, Knighton RW. Macular thickness changes in glaucomatous optic neuropathy detected using optical coherence tomography. Arch Ophthalmol 2003;121(1):41-6. [PubMed: 12523883]

113. Lederer DE, Schuman JS, Hertzmark E, et al. Analysis of macular volume in normal and glaucomatous eyes using optical coherence tomography. Am J Ophthalmol 2003;135(6):838-43. [PubMed: 12788124]

114. Schuman JS, Wollstein G, Farra T, et al. Comparison of optic nerve head measurements obtained by optical coherence tomography and confocal scanning laser ophthalmoscopy. Am J Ophthalmol 2003;135(4):504-12. [PubMed: 12654368]

115. Essock EA, Sinai MJ, Bowd C, et al. Fourier analysis of optical coherence tomography and scanning laser polarimetry retinal nerve fiber layer measurements in the diagnosis of glaucoma. Arch Ophthalmol 2003;121(9):1238-45. [PubMed: 12963606]

116. Zeimer RC, Mori MT, Khoobehi B. Feasibility test of a new method to measure retinal thickness noninvasively. Invest Ophthalmol Vis Sci 1989;30(10):2099-105. [PubMed: 2793353]

117. Zeimer R, Shahidi M, Mori M, et al. A new method for rapid mapping of the retinal thickness at the posterior pole. Invest Ophthalmol Vis Sci 1996;37(10):1994-2001. [PubMed: 8814139]

118. Neubauer AS, Priglinger S, Ullrich S, et al. Comparison of foveal thickness measured with the retinal thickness analyzer and optical coherence tomography. Retina 2001;21(6):596-601. [PubMed: 11756882]

119. Fritsche P, van der Heijde R, Suttorp-Schulten MS, Polak BC. Retinal thickness analysis (RTA): an objective method to assess and quantify the retinal thickness in healthy controls and in diabetics without diabetic retinopathy. Retina 2002;22(6):768-71. [PubMed: 12476104]

120. Polito A, Shah SM, Haller JA, et al. Comparison between retinal thickness analyzer and optical coherence tomography for assessment of foveal thickness in eyes with macular disease. Am J Ophthalmol 2002;134(2):240-51. [PubMed: 12140031]

121. Zeimer R, Asrani S, Zou S, et al. Quantitative detection of glaucomatous damage at the posterior pole by retinal thickness mapping: a pilot study. Ophthalmology 1998;105(2):224-31. [PubMed: 9479279]

122. Mistlberger A, Liebmann JM, Greenfield DS, et al. Heidelberg retina tomography and optical coherence tomography in normal, ocular-hypertensive, and glaucomatous eyes. Ophthalmology 1999;106(10):2027-32. [PubMed: 10519603] 


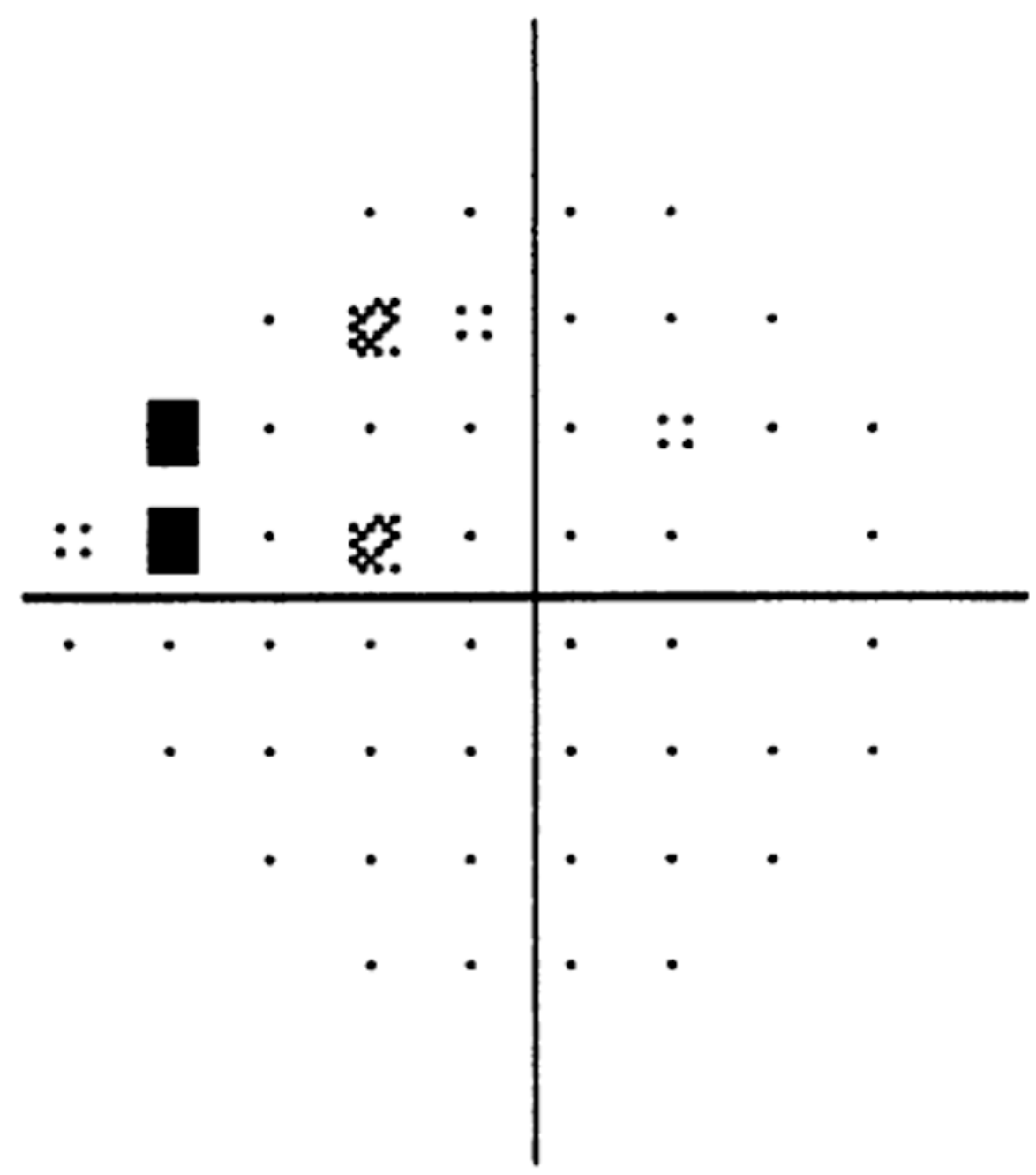

Fig 1.

Visual field test of patient with glaucoma (OD). Visual field shows a superior nasal defect and questionable superior arcuate defect. This field corresponds to the later figures showing HRT and OCT scans of this patient. 


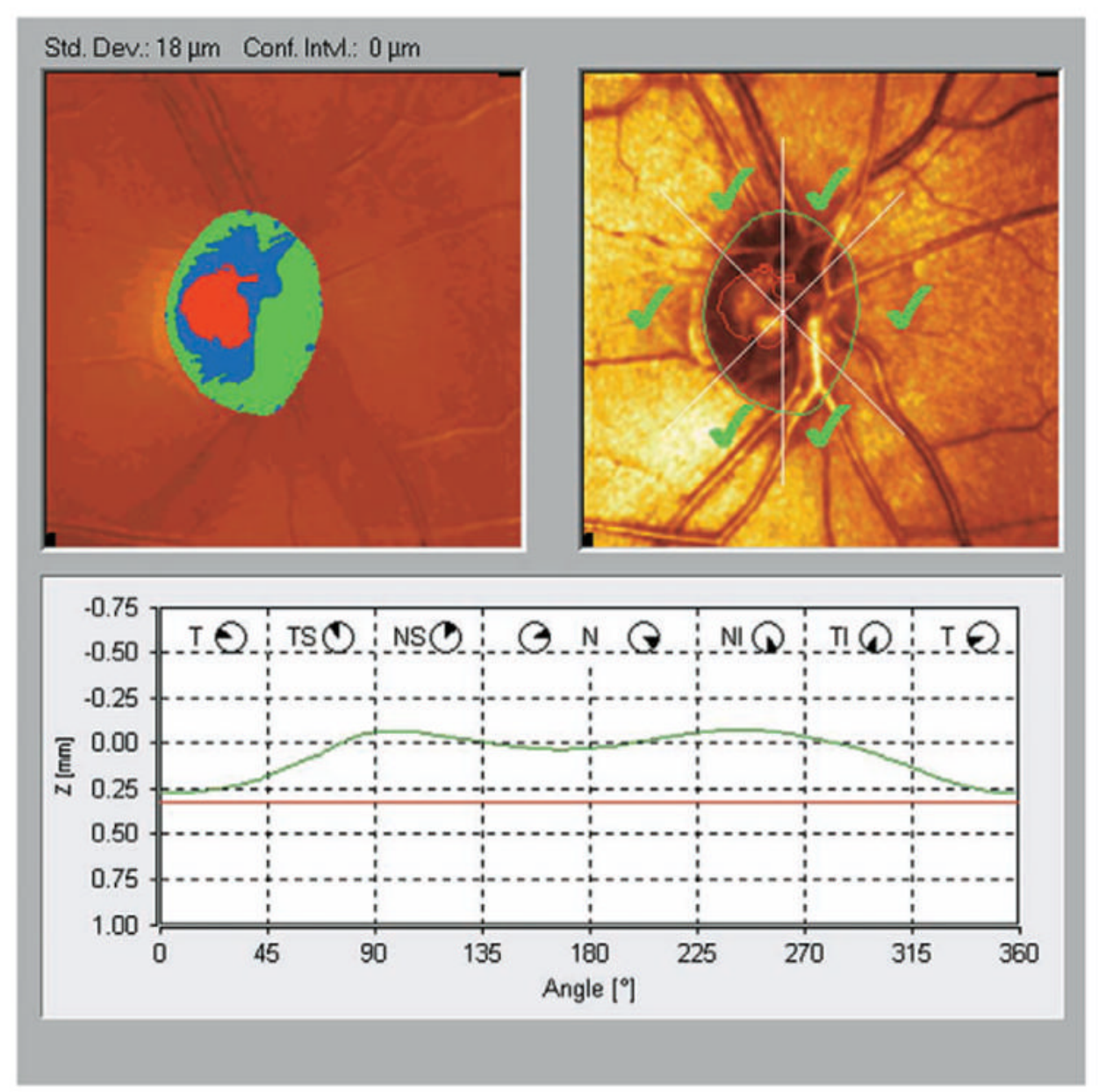

Fig 2.

HRT scan of normal subject (OD). On the upper left image, the topographic ONH map is shown. The red area marks the cup, and the green and blue areas mark the neuroretinal rim. The upper right image, the reflectance image, is shown with the tracing (green) of the optic disk margin and the outline (red) of the optic cup. All of the ONH sectors are marked with the green checkmark, signifying that they are within the normal limits based on Moorfields regression analysis. At the bottom of the figure, a graph depicts the surface height along the contour line on the ONH margin. Note the normal "double-hump" appearance, with higher thickness in the superior and inferior regions. 


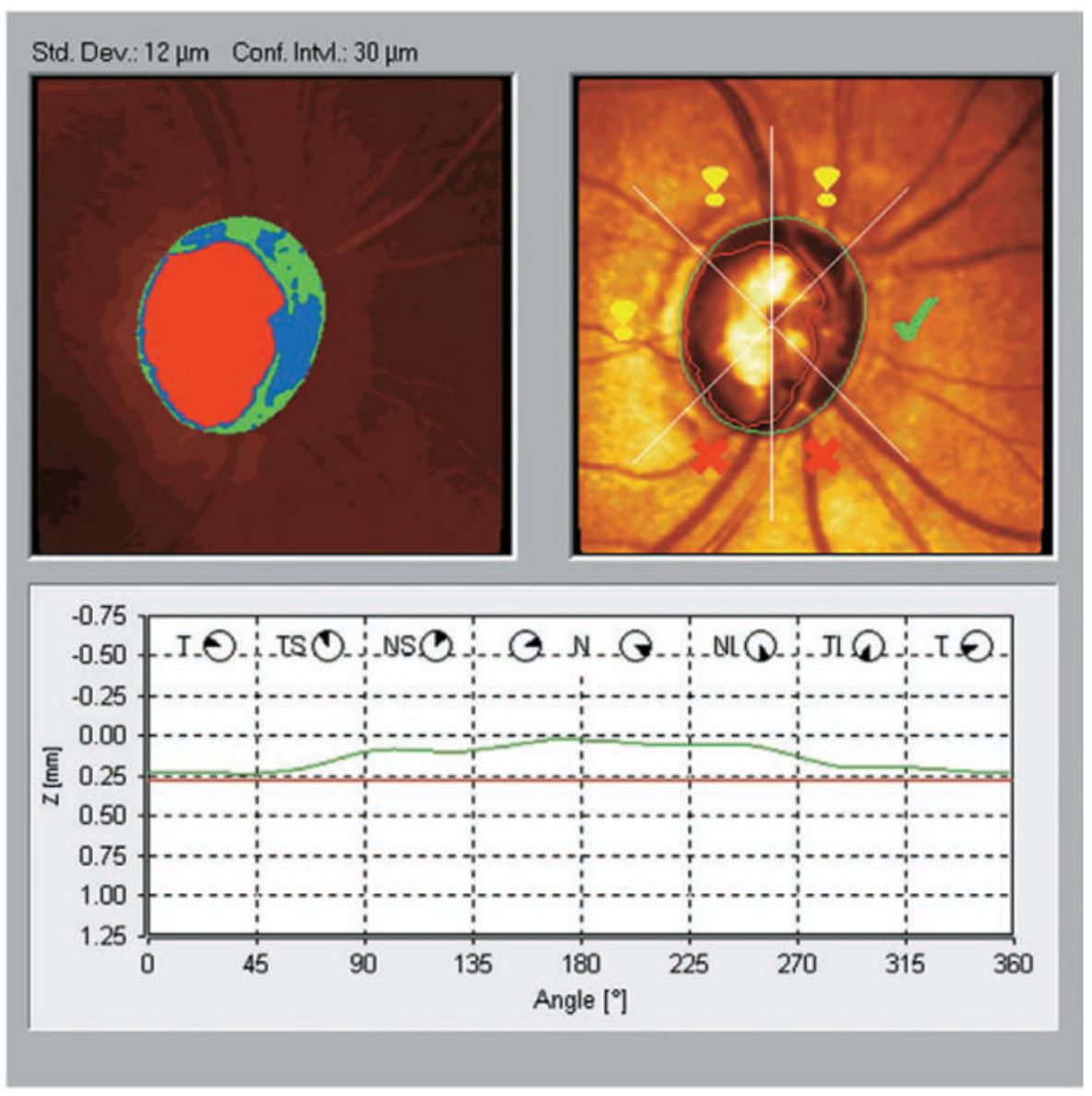

Fig 3.

HRT scan of subject with glaucoma (OD). On the upper left image, note the extensive cupping of the $\mathrm{ONH}$ and the thinnest area of neuroretinal rim in the inferotemporal region. Moorfields regression analysis marked the inferotemporal and the nasal inferior sectors as abnormal and the temporal and the superior sectors as borderline. The typical double-hump configuration in the lower graph was eliminated mainly owing to tissue loss at the $\mathrm{ONH}$ poles. These findings correspond with the superior nasal visual field defect shown in Fig. 1 and show additional superior ONH damage that might precede the perimetric appearance. 


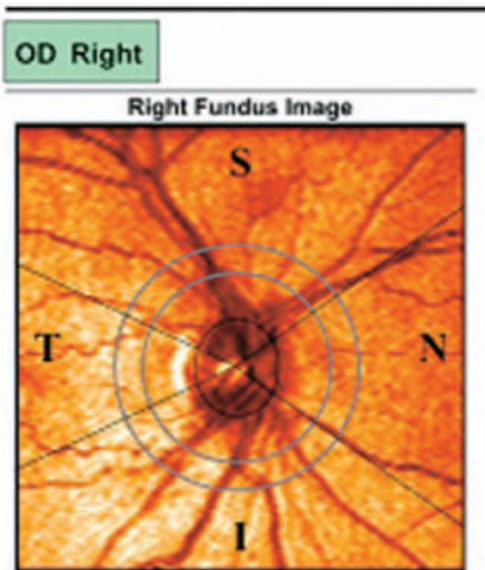

\begin{tabular}{|c|c|c|}
\hline $\begin{array}{c}\text { TSNIT } \\
\text { Parameters }\end{array}$ & $\begin{array}{c}\text { OD } \\
\text { Actual Val. }\end{array}$ & $\begin{array}{c}\text { OS } \\
\text { Actual Val. }\end{array}$ \\
\hline TSNIT Average & 53.37 & 49.64 \\
\hline Superior Average & 68.00 & 67.91 \\
\hline Inferior Average & 67.18 & 60.25 \\
\hline TSNIT Std. Dev. & 25.03 & 25.11 \\
\hline Inter-Eye Symmetry & \multicolumn{2}{|c|}{0.92} \\
\hline NFI & 18 & 21 \\
\hline
\end{tabular}

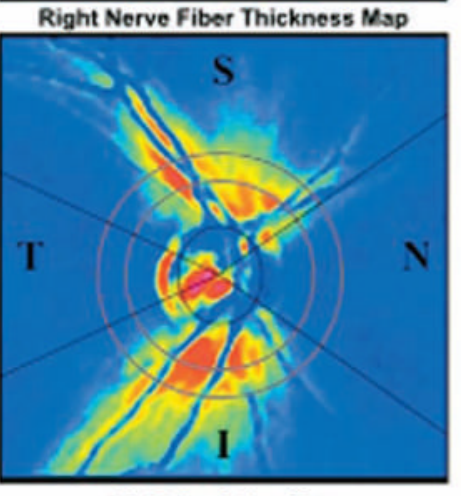

\begin{tabular}{|c|c|c|c|c|}
\hline$p>=5 \%$ & $p<5 \%$ & $p \times 2 \%$ & $p<1 \%$ & $p<0.58$ \\
\hline
\end{tabular}
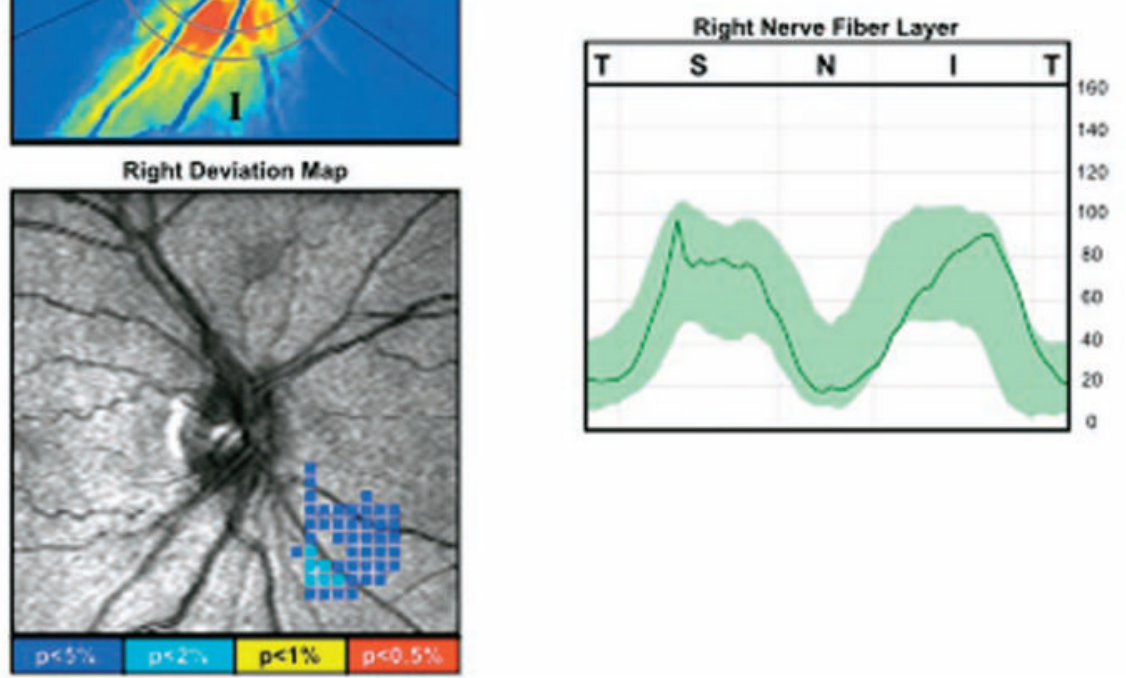

Fig 4.

GDx VCC scan of normal subject (OD). This figure shows the fundus image (top left), a pseudocolor representation of the nerve fiber layer thickness (middle left), and a map of areas that deviate from normal thickness values (bottom left). The nerve fiber layer graph shows measured thickness values (green line) superimposed on the normative range (green band). 


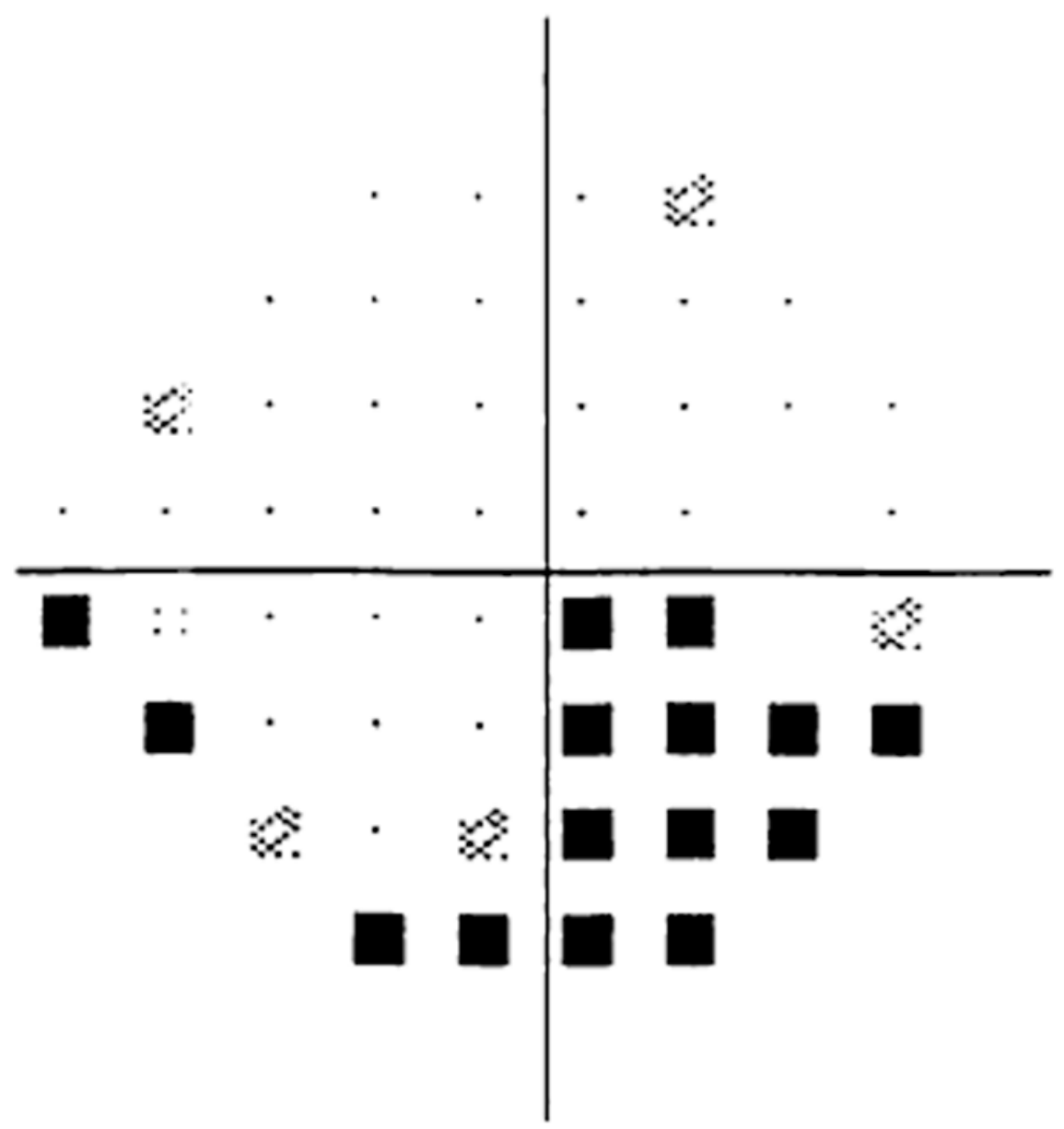

Fig 5.

Visual field test of subject with glaucoma (OD). Visual field shows an inferior hemifield defect. This field corresponds to the following figure showing a GDx VCC scan of a glaucomatous subject. 


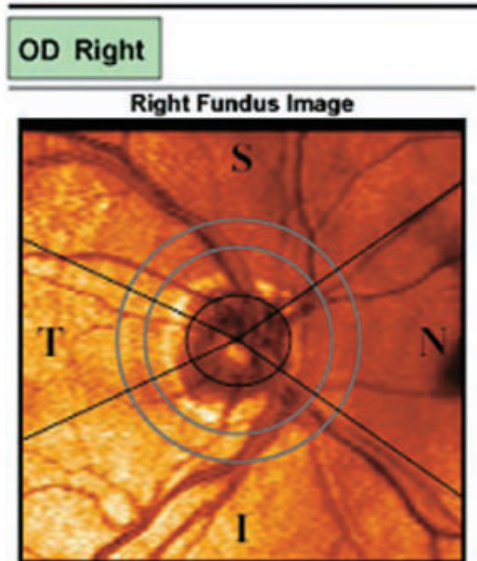

Right Nerve Fiber Thickness Map

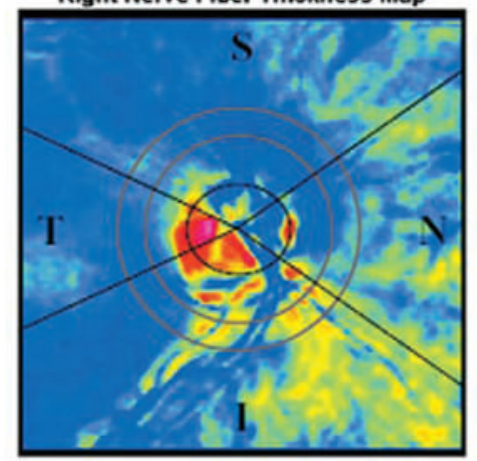

Right Deviation Map

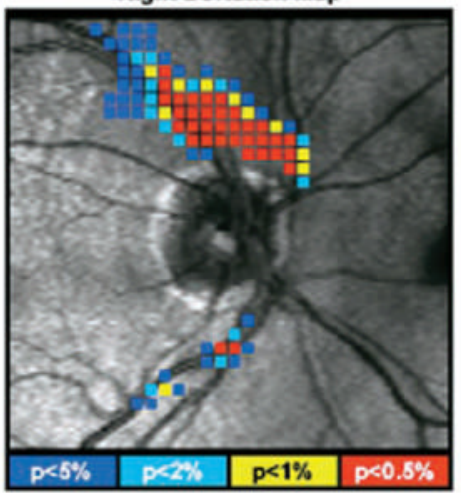

\begin{tabular}{|c|c|c|}
\hline $\begin{array}{c}\text { TSNIT } \\
\text { Parameters }\end{array}$ & $\begin{array}{c}\text { OD } \\
\text { Actual Val. }\end{array}$ & $\begin{array}{c}\text { OS } \\
\text { Actual Val. }\end{array}$ \\
\hline TSNIT Average & 44.25 & 52.41 \\
\hline Superior Average & 34.66 & 56.38 \\
\hline Inferior Average & 54.64 & 65.21 \\
\hline TSNIT Std. Dev. & 19.63 & 19.61 \\
\hline Inter-Eye Symmetry & & 0.60 \\
\hline NFI & 66 & 24 \\
\hline
\end{tabular}

\begin{tabular}{|l|l|l|l|l|}
\hline$p>=5 \%$ & $p<5 \%$ & $p<2 \%$ & $p<1 \%$ & $p<0.5 \%$ \\
\hline
\end{tabular}

Thickness Map Legend (microns)

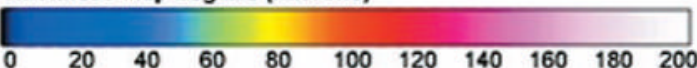

Right Nerve Fiber Layer

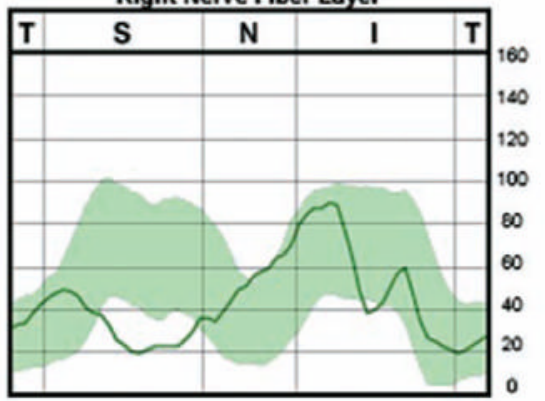

Fig 6.

GDx VCC scan of subject with glaucoma (OD). Note the blue shaded area in the superior region of the thickness map that signifies a relatively thin nerve fiber layer. This thinning of the superior region is highlighted in the deviation map and the nerve fiber layer graph showing thickness values outside of the norm in the superior region. This defect corresponds well with this subject's visual field as shown in Fig. 5. 


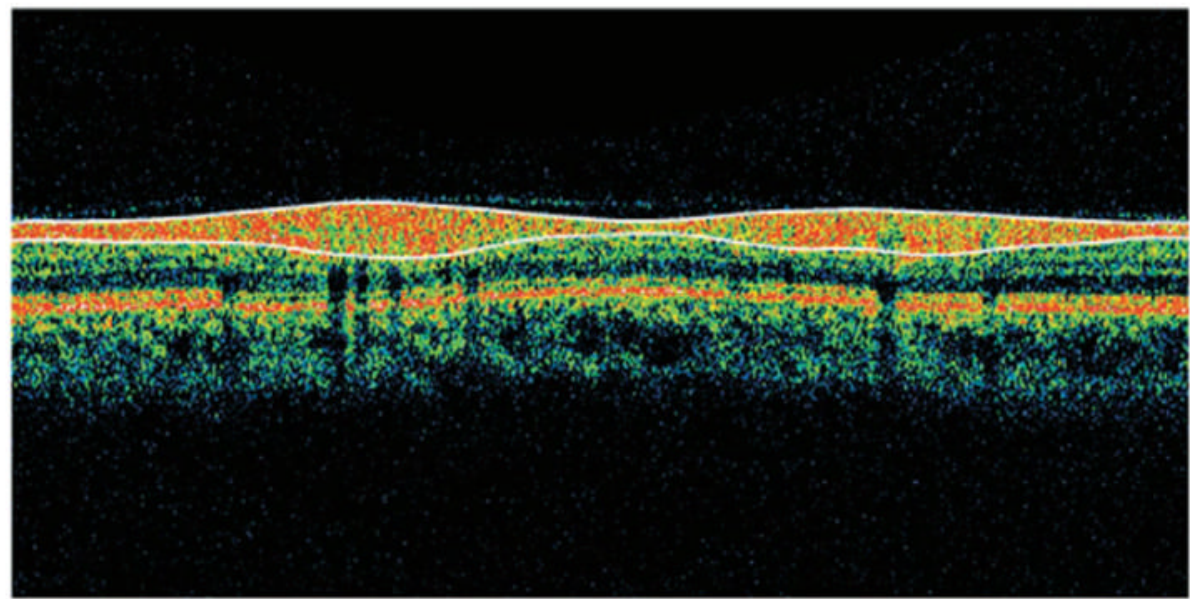

\section{Microns}
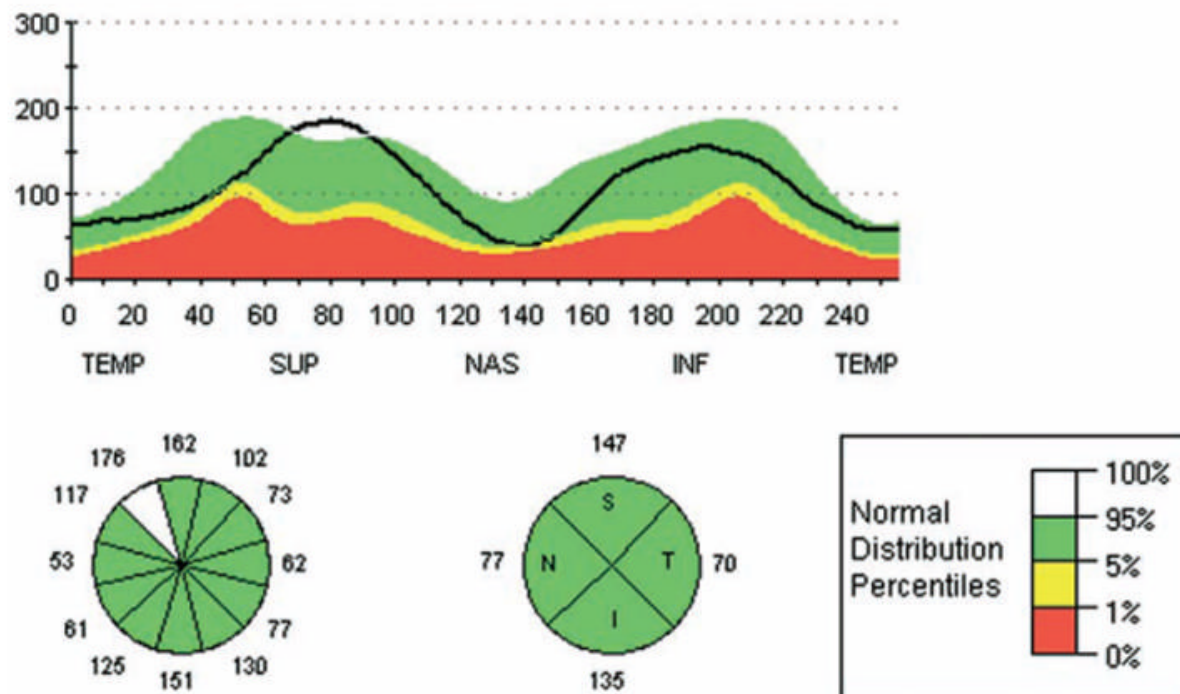

Fig 7.

OCT retinal nerve fiber layer thickness of a normal subject. At the top of the figure, a colorcoded cross-sectional map displays 256 adjacent A-scans. The uppermost red layer delineated with the white lines is the nerve fiber layer. Below this image, a graph shows the patient's nerve fiber layer thickness values (black line) in comparison with normative values. The circular charts show average nerve fiber layer thickness values for the depicted regions, and the colors denote the correspondence with the normative database. 

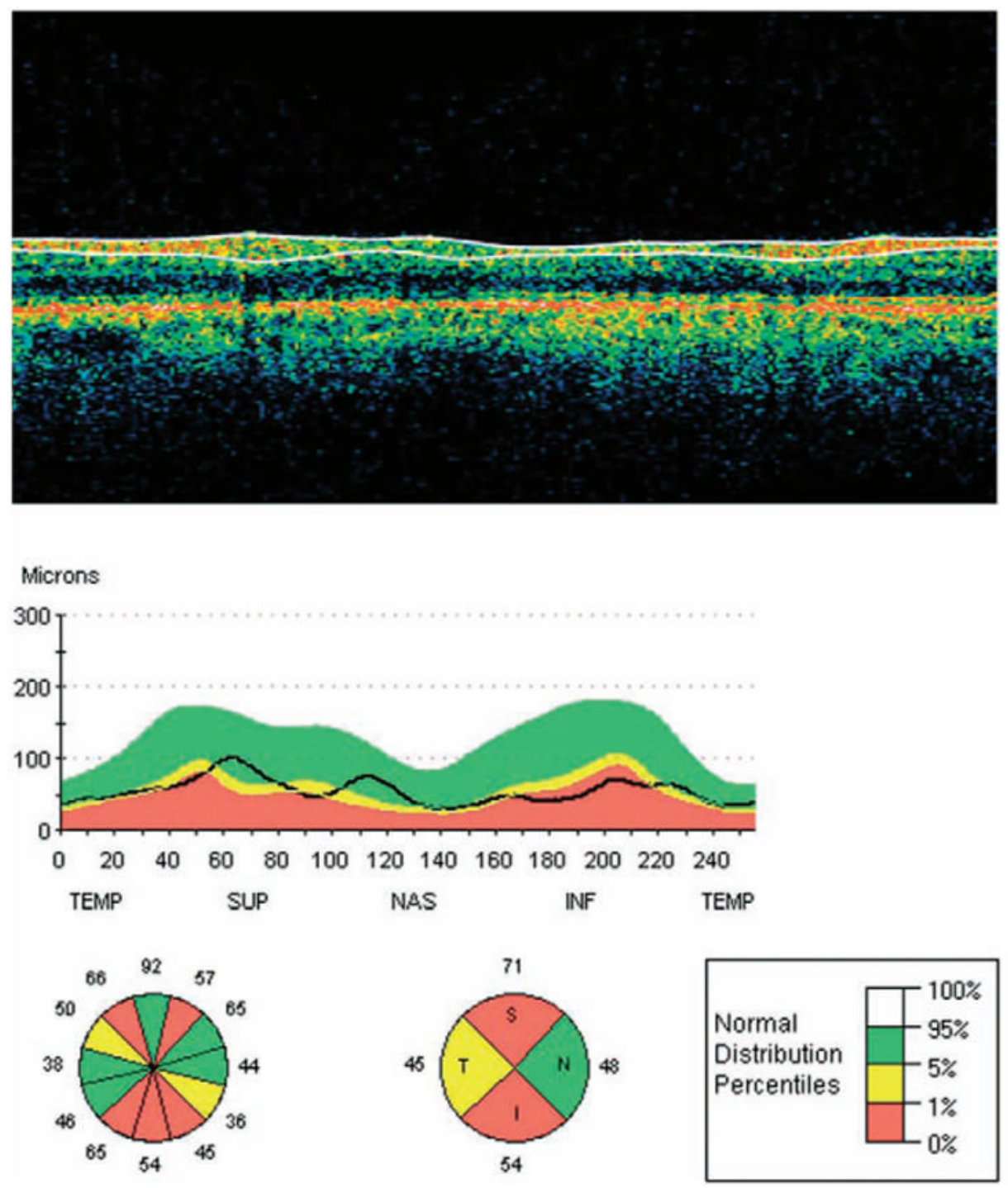

Fig 8.

OCT retinal nerve fiber layer thickness of a subject with glaucoma. The cross-sectional map shows diminution of the nerve fiber layer when compared with the normal thickness. The thinning is pronounced for the most part in the inferior sectors corresponding to the visual field defect shown in Fig. 1. Abnormal thinning is also evident in the upper sectors, possibly reflecting structural damage not yet evident by perimetry. 

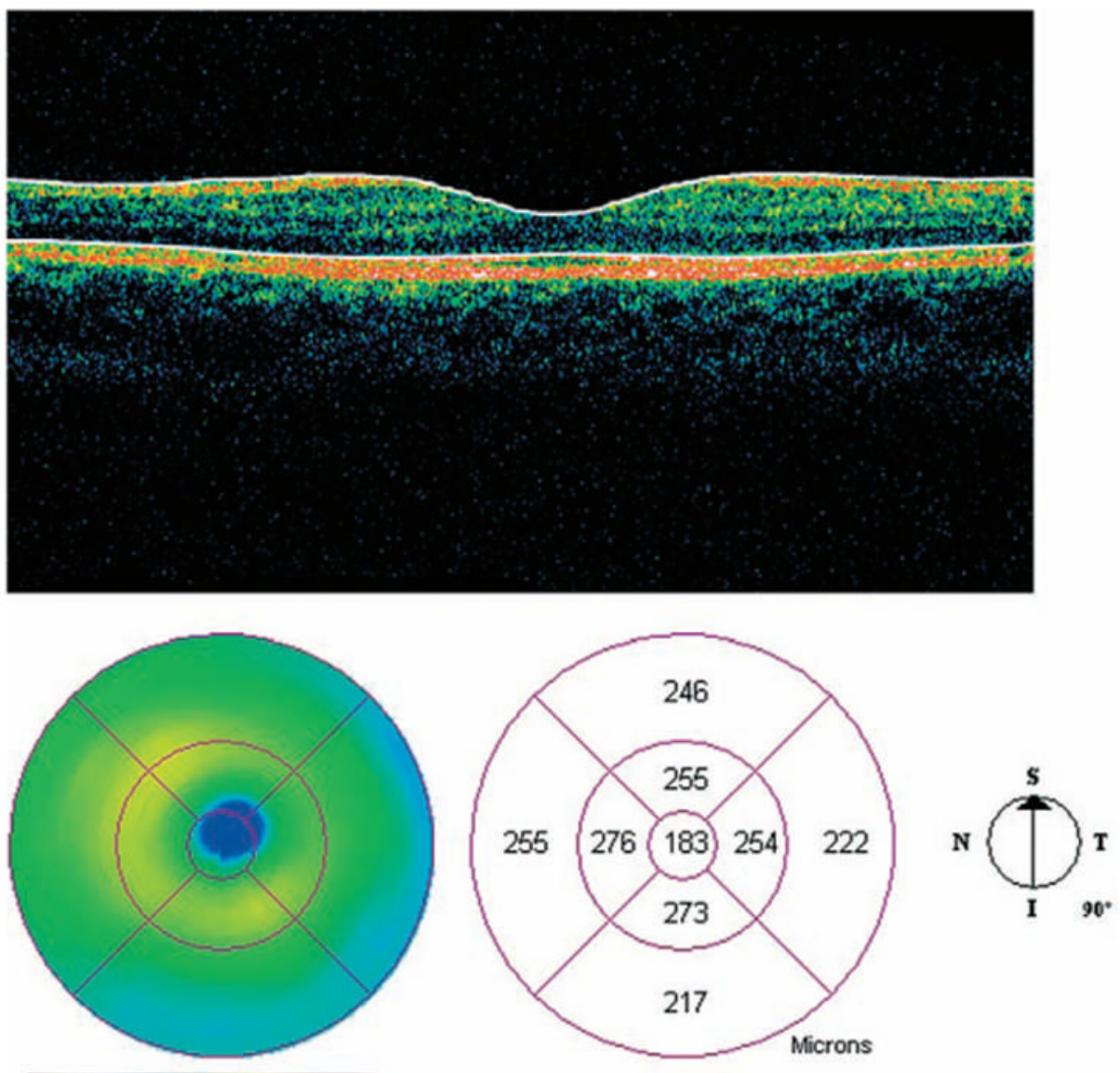

Fig 9.

OCT macular map of a normal subject (OS). The uppermost image of the figure is a colorcoded, cross-sectional map along the vertical line, one of the six radial scans that compose the macular map. The central thinning corresponds to the foveola, and the white lines mark the vitreoretinal and the retinal pigment epithelium boundaries of the retina. The lower left map is the color-coded macular thickness map wherein blue signifies thinner retina and yellowgreen thicker retina. The center map gives the quantitative measurements in nine sectors. 

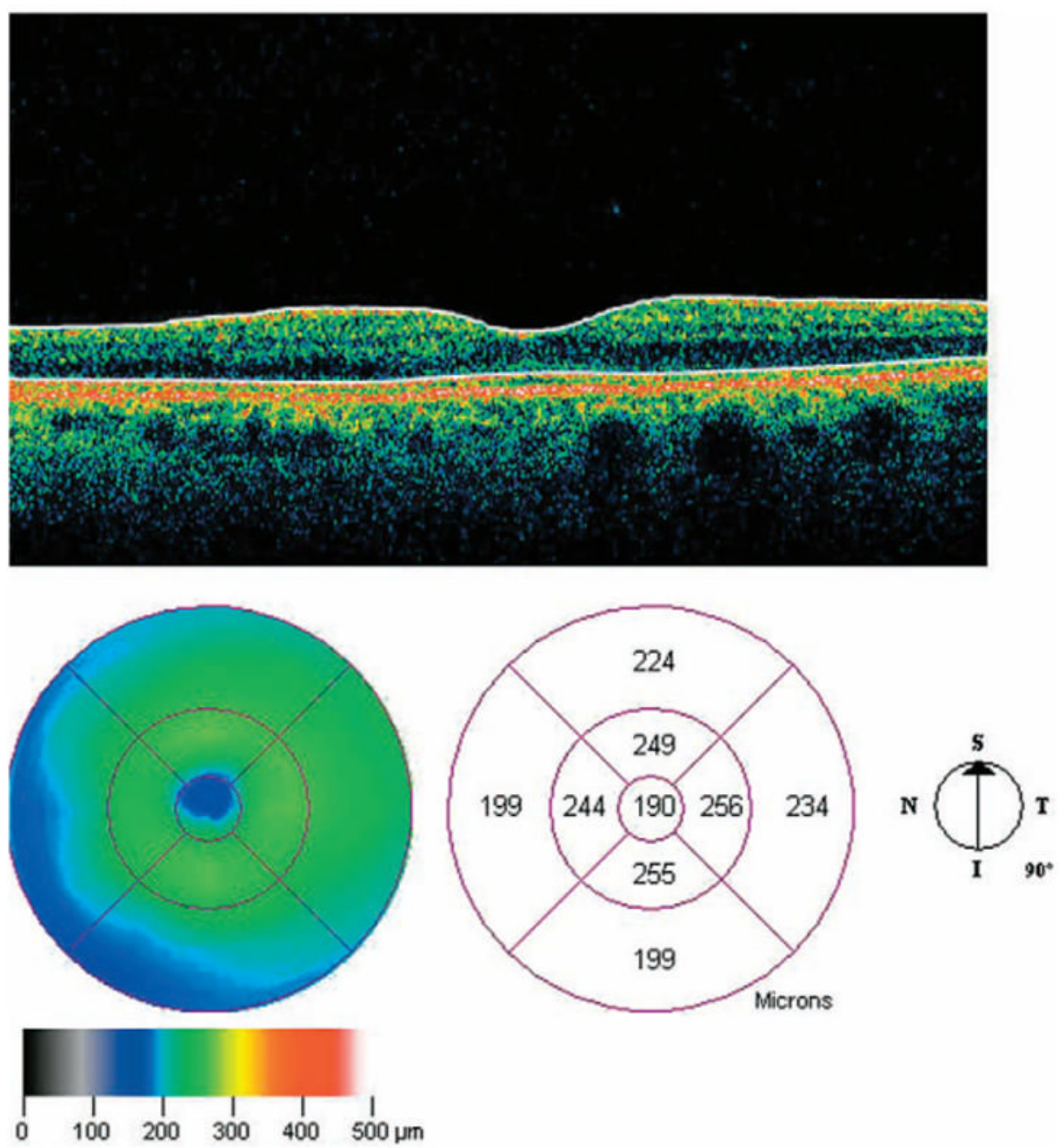

Fig 10.

OCT macular map of a subject with glaucoma (OD). The uppermost image shows a marked diminution of the upper red band, signifying damage to the nerve fiber layer. The color-coded map (lower left) demonstrates a thinning of the macula, most extensively in the inferotemporal region, which corresponds to the visual field defect shown in Fig. 1. This finding also can be appreciated from the numerical values in the lower center map. 
A

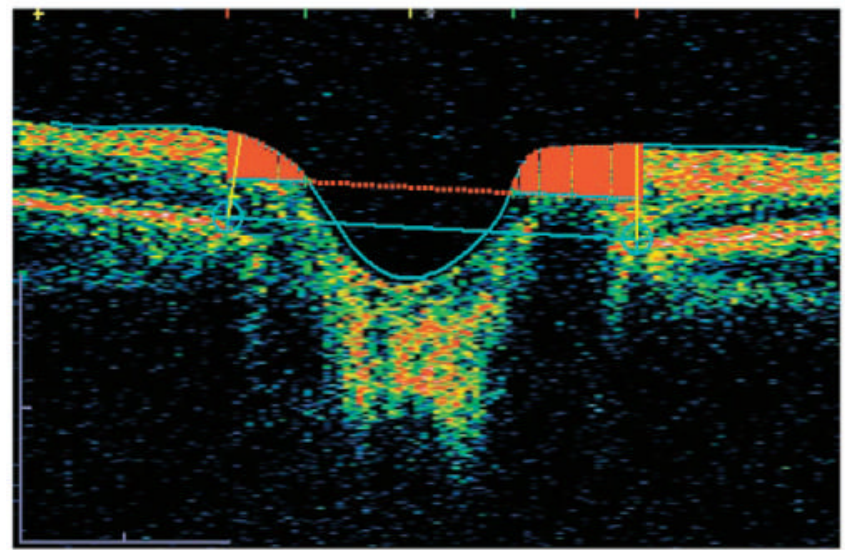

B

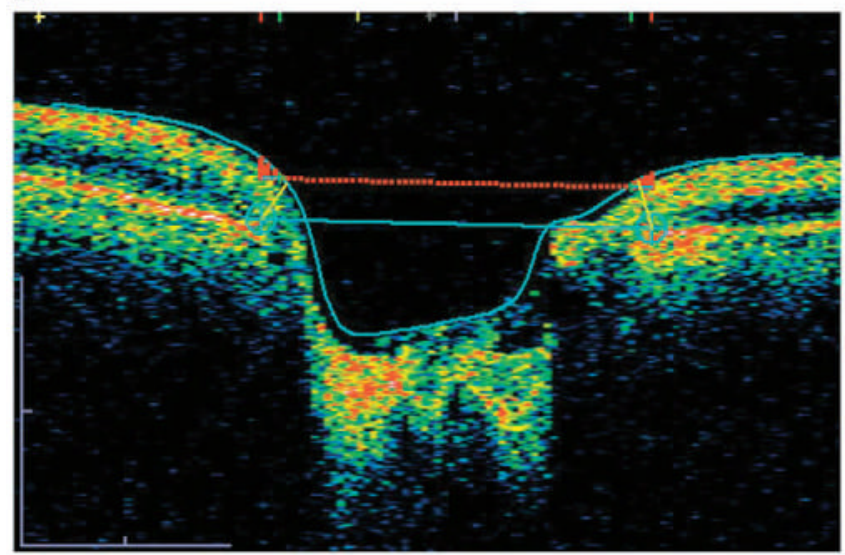

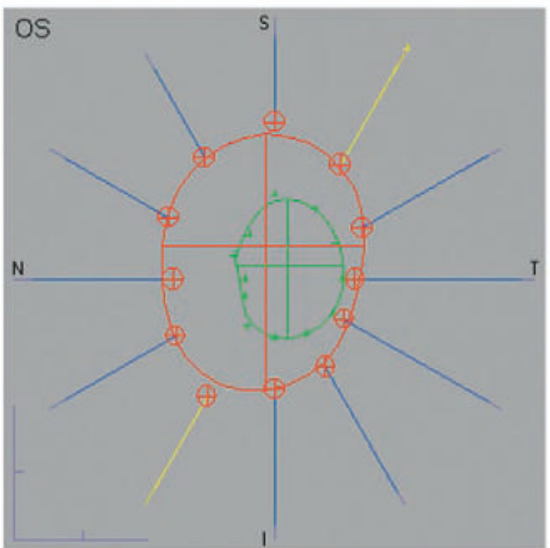

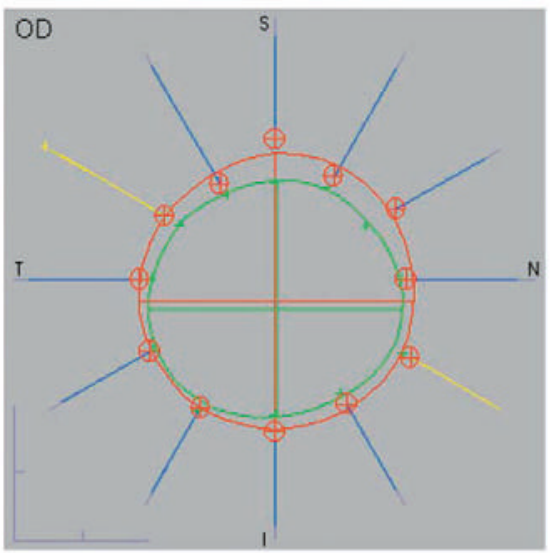

Fig 11.

(A) OCT analysis of the ONH of a normal subject (OS). The image on the left is a inferonasal to superotemporal optical cross-section map, one of the six radial scans that compose the ONH map. The edge of the retinal pigment epithelium/choriocapillaris layer is marked by the blue cross, and a straight line connects between the margins. A parallel line located anteriorly to this line separates the rim (above the line) and the cup (below the line). On the right, the contours of the ONH (red circle) and optic cup (green circle) are displayed as created from the data obtained from all six radial scans (blue lines; yellow line represents the scan depicted in the image on the left). (B) OCT analysis of the ONH of a subject with glaucoma (OD). Note the widened optic cup and increased slope of the contour of the rim in the image on the left, representing axonal loss in the optic cup of a glaucomatous patient. The contour map on the right demonstrates a large cup, with thinning of the neuroretinal rim most pronounced in the inferotemporal region, which corresponds to the visual field defects in this patient (see Fig. 1). 